\title{
THE CLINICAL USES OF OXIMETRY
}

\author{
BY \\ MALCOLM B. MCILROY* \\ From the Institute of Cardiology and the National Heart Hospital \\ Received September 1, 1958
}

In some patients with congenital heart disease the arterial oxygen saturation can be altered by simple measures, such as Valsalva's manœuvre, exercise, squatting, amyl nitrite inhalation, or oxygen breathing. This paper reports a study of the clinical use of oximetry to measure the changes after such manœuvres and aims to show how the results obtained may be useful in diagnosis. The methods used have been kept as simple as possible in an attempt to develop techniques that can be used in an out-patient clinic. More than 300 patients have been studied; the diagnosis was based on the clinical findings, confirmed by cardiac catheterization or angiocardiography. In a few cases the diagnosis was established either at operation or autopsy and, while there is little doubt that it is correct in the simpler conditions, there must be some question of the accuracy of the diagnosis in some of the more complicated cases.

The methods used to produce changes in the arterial oxygen saturation were (1) Valsalva's manœuvre at rest and after exercise, (2) exercise, (3) squatting and standing, (4) amyl nitrite inhalation, and (5) breathing 100 per cent or 30 per cent oxygen. Not all these methods were used in every case, but an attempt was made to use oximetry as an adjunct to clinical examination, radiography, and electrocardiography, so that the procedure varied with the nature of the clinical problem.

\section{Methods}

Ear oximeters have a reputation for instability and inaccuracy, which is reasonably well-deserved. The measurement of the absolute level of arterial oxygen saturation from the transmission of light through the ear presents many technical difficulties. Variations in ear thickness, ear texture, skin colour, and hæmoglobin level make it almost impossible to devise an instrument that will always give an accurate record. The recording of changes in saturation is not so difficult and the methods used in this study have concentrated more on changes, than on the actual level of arterial oxygen saturation.

The ear oximeter used (Stanley Cox) was a single scale instrument based on a circuit developed by Stott (1953) and was modified to give a continuous record of arterial oxygen saturation on a pen recorder or a multi-channel photographic recorder. If possible, the lobe of the ear was used; if this proved to be too small, the instrument was put on the pinna of the ear. Vasodilatation was produced with rubefacient cream, which was left on the ear for about five minutes. The degree of vasodilatation varied as the ear heated up and the drift that resulted was counteracted by frequent rebalancing of the instrument. The right ear was used, unless there was a possibility of reversed shunt through a patent ductus arteriosus, in which case measurements were made on the left ear also. The patient usually sat in a chair, but when measurements were made during cardiac catheterization, the patient lay flat.

Calibration. The oximeter was calibrated against arterial blood samples analysed by Haldane's method. The calibration curve is shown in Fig. 1; it can be seen that the instrument was reasonably accurate, when the arterial oxygen saturation was above 80 per cent. Each point in Fig. 1 represents a different patient, so that the oximeter was tested on patients with a wide range of hæmoglobin levels and on many different ears. A day to day check on the working of the instrument was also obtained by observing the fall in arterial oxygen saturation that occurs with breath-holding. When a normal subject holds his breath, the arterial saturation falls until, at the breaking point, it has reached a level that is more or less constant for

* Present address: Cardiovascular Research Institute, University of California Medical Center, San Francisco, U.S.A. 


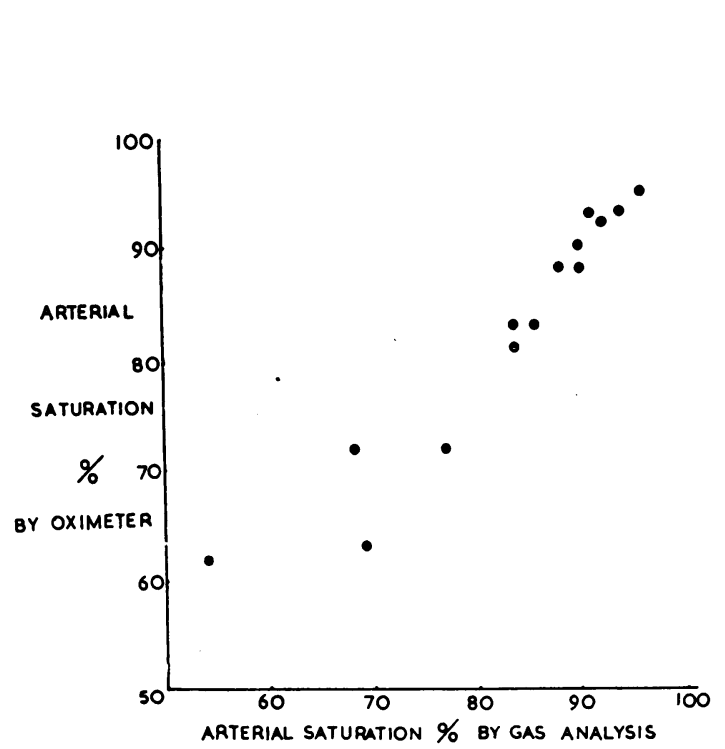

Fig. 1.-Calibration curve of oximeter. Each point represents a different patient.

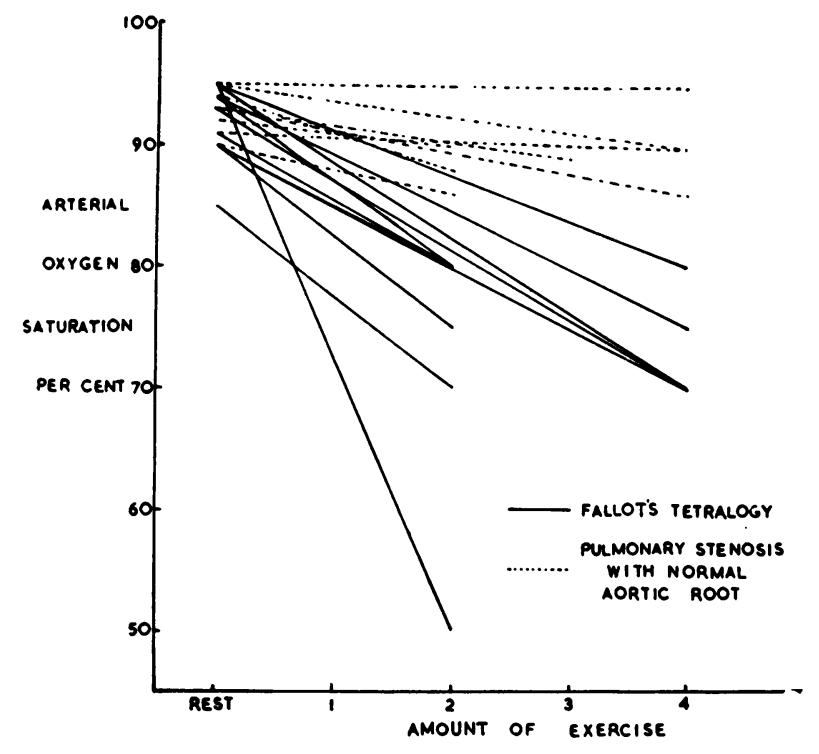

Fig. 2.-Arterial oxygen saturation plotted against amount of exercise in 26 patients with pulmonary stenosis. The saturation falls more readily on exercise in patients with Fallot's tetralogy.

that individual. When breathing is resumed, the saturation starts to rise again after about three seconds and rapidly returns to its original value. The observation that the oximeter showed these changes with breath-holding proved a useful check that it was working properly.

Artefacts. Changes in ear thickness, due to distension of the ear by the rise in venous pressure during Valsalva's manœuvre, were found to have an effect on the oximetric reading. An increase in ear thickness produced an apparent increase in saturation and variations in apparent saturation also occurred with each heart beat in some patients. These artefacts can be seen in the tracing shown in Fig. 3 from a normal subject.

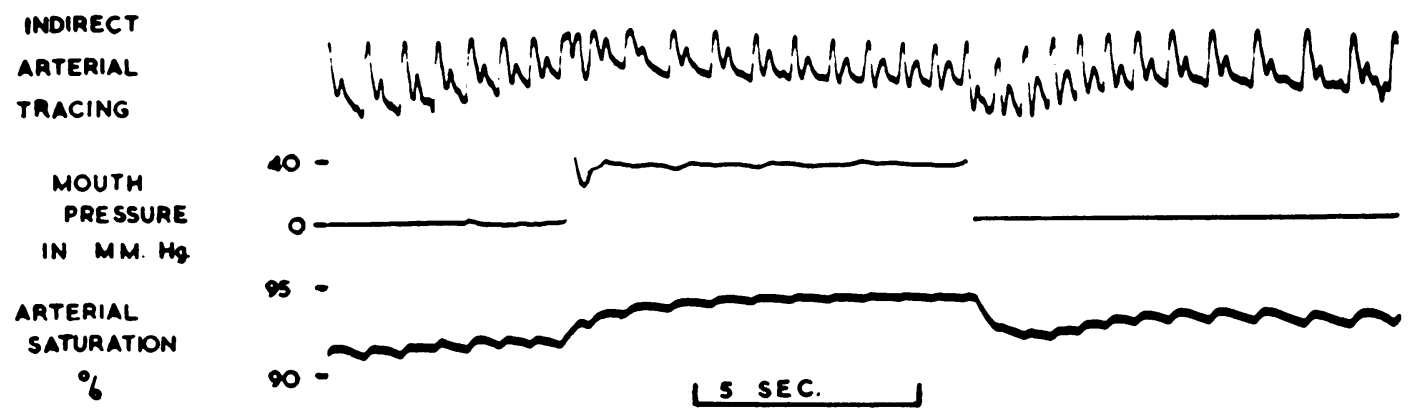

FIG. 3.-Tracing of arterial pulse, mouth pressure, and arterial oxygen saturation in a normal subject, showing artefacts during and after Valsalva's manœuvre.

There was an apparent increase in saturation during the period of strain and the variations in saturation with each heart beat were greatest during the overshoot after Valsalva's manœuvre. These artefacts were usually greater when the patient lay flat.

Valsalva's Manauvre. When the effect of Valsalva's manœuvre was being studied, the systemic arterial pulse was recorded by an indirect method (Brabrook-Norman, 1954), using a carbon microphone over the radial or brachial artery. In some patients, studied during cardiac catheterization, a direct intra-arterial tracing was obtained. Although the indirect method was less satisfactory, it had the advantage of simplicity. The main use of an arterial tracing was to decide whether the arterial pressure response to Valsalva's manœuvre was normal or "square-wave" in type (Hamilton et al., 1944; Sharpey-Shafer, 1955). The presence of bradycardia after the period of strain indicated a normal response, while its absence denoted a 
square-wave response. The mouth pressure was also recorded during Valsalva's manœuvre to check the size and timing of the blow. A standard pressure of $40 \mathrm{~mm}$. Hg was maintained for $10 \mathrm{sec}$. More than 95 per cent of the patients over the age of 5 years were able to perform a satisfactory Valsalva, but care had to be taken to see that the patient did not close the glottis and blow with the cheeks. This can be prevented by introducing a small leak into the system. Early in this study, the effects of longer periods of strain than $10 \mathrm{sec}$. and higher pressures than $40 \mathrm{~mm}$. were tried, but the amount of extra information obtained was small. The effect of Müller's manœuvre was also tried, but most patients found it so difficult to do, that it too was abandoned. No untoward effects were observed after Valsalva's manœuvre, with the exception of one patient with atrial septal defect and pulmonary hypertension, who developed cardiac pain when the arterial oxygen saturation fell 25 per cent after Valsalva's manœuvre. A cardiogram showed S-T depression during the few beats when the patient had pain and the pain was clearly cardiac in origin.

Exercise. In most patients the arterial oxygen saturation was measured after exercise and Valsalva's manœuvre was repeated during recovery. The exercise consisted of walking up stairs, the number of stairs varying with the clinical state of the patient. The standard amount of exercise was 50 stairs, after which the patient sat down again and the saturation was remeasured. The arterial oxygen saturation was often rising slowly during the period of recovery, when Valsalva's manœuvre was performed after exercise and the manœuvre was repeated several times, often after a second period of exercise.

Oxygen Breathing. The effect of breathing either 100 or 30 per cent oxygen on the arterial oxygen saturation was measured in cyanosed patients. The patient breathed from a Douglas bag through a valve assembly and the time of switching to different oxygen mixtures was marked on the record. The initial arterial oxygen saturation and the rate of rise were measured. If the rise in arterial saturation was exponential, the maximum rise in percentage per minute was measured; if the rise was linear, the rate of rise in the period $\frac{1}{2}$ to $1 \frac{1}{2}$ minutes after starting to breathe oxygen was measured. The oximeter showed a tendency to drift in the direction of an apparent increase in saturation. In order to compensate for this, the arterial saturation was recorded during control periods, before and after oxygen breathing. The rate of drift during the control periods, breathing air, was substracted from the rise with oxygen breathing.

Amyl Nitrite Inhalation. The effect of amyl nitrite inhalation on the arterial oxygen saturation was measured in patients in whom there was a question of a right-to-left shunt. An indirect arterial tracing was usually obtained at the same time. In patients studied during cardiac catheterization, intra-cardiac or direct arterial tracings were also obtained. The occurrence of flushing and tachycardia were taken as evidence of a fall in systemic resistance in response to amyl nitrite. This response was not invariable and no conclusions could be drawn in patients who failed to respond to the drug. Inhalation was always stopped when a fall in saturation was observed.

Squatting and Standing. The effect of posture on the arterial oxygen saturation was studied after exercise. After walking upstairs, the patient squatted while the oximeter was put in position. The patient then stood up and the change in saturation was recorded. In some cases the patient then squatted again and in others the order was reversed, the patient first standing and then squatting.

\section{RESULTS}

Normal Subjects and Patent Foramen Ovale. No significant change in arterial oxygen saturation was observed in ten normal subjects after Valsalva's manœuvre either at rest or after exercise. It was thought originally that temporary right-to-left shunts after Valsalva's manœuvre, of the type described by Lee and Gimlette (1957) in patients with atrial septal defect, might occur in normal subjects with patent foramen ovale. The findings in two patients with pulmonary stenosis, in whom a patent foramen ovale was proved by cardiac catheterization, were thought to make this unlikely. In both, the catheter was passed with difficulty into the left atrium and the pressure and wave form shown to be higher and different from that in the right atrium. In both patients the response to Valsalva's manœuvre was normal and no right-to-left shunt could be demonstrated, either at rest or after exercise. In view of these results, further studies in normal subjects, aiming to show that a patent foramen ovale was present, were not carried out. Lee (1958) has found that it is possible to demonstrate a right-to-left shunt, presumably through a foramen ovale, in a normal subject by a combination of a maximal Valsalva and $G$ suit inflation.

\section{Atrial Septal Defect}

Lee and Gimlette (1957) have shown that it is possible to produce a temporary reversal of the dominant left-to-right shunt by Valsalva's manœuvre in many patients with atrial septal defect (ASD). A typical tracing showing this shunt reversal in such a patient is shown in Fig. 4 . The 
indirect pulse tracing and mouth pressure are shown, together with a continuous record of the arterial oxygen saturation. The response to Valsalva's manœuvre was normal, because there was bradycardia after the period of strain. The saturation rose slightly during the period that the mouth pressure was raised; this may have been due to cutting off the small right-to-left shunt, which is

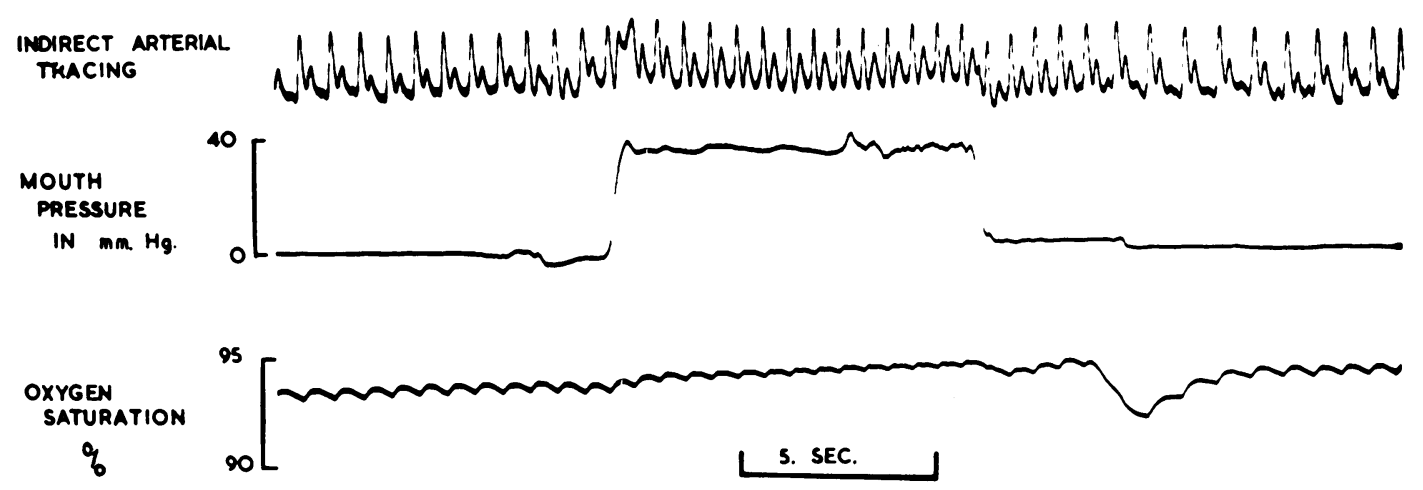

FIG. 4.-Shunt reversal after Valsalva's manœuvre in a patient with atrial septal defect.

sometimes found in patients with ASD. The ear artefact in this patient was small, there being little change in the oximetric record coincident with the start and finish of the blow. Shunt reversal occurred 3 seconds after the end of the period of strain, when the arterial oxygen saturation fell 3 per cent, the fall being spread over 3 seconds. The suggested explanation for this sequence of events depends on what happens in the heart during Valsalva's manœuvre. It is thought that the rise in intra-thoracic pressure, when the patient starts to blow, cuts off the systemic venous return to the right atrium. The heart tends to empty, as it continues to beat without filling, and the fall in systemic arterial pressure that occurs represents emptying of the heart and lungs. At the end of the period of strain, both atria must be emptier than they were at the start of the manœuvre. When the intra-thoracic pressure is released and the systemic venous return is restored, venous blood is thought to pour into the right atrium and produce a temporary increase in right atrial pressure. If there is an atrial septal defect, the rise in right atrial pressure produces a right-to-left shunt, and so lowers the arterial oxygen saturation. The shunted blood takes time to reach the ear, so that the drop in arterial saturation is delayed by about 3 seconds. The pressure difference between the right and left atria at the end of Valsalva's manœuvre in a patient with a small atrial septal defect is shown in Fig. 5. This tracing was obtained with a twin lumen catheter and a differential manometer (New Electronic Products) and when the patient stopped blowing, there was a pressure gradient from the right-to-left atrium of $4 \mathrm{~mm}$. Hg lasting about $0.25 \mathrm{sec}$. The fall in arterial saturation followed about 3 seconds later. This pressure gradient from right to left was so short lived, that its effect could well have varied with the time in the cardiac cycle at which it occurred. It was found that the fall in arterial saturation after Valsalva's manœuvre in a given patient with ASD varied. On one occasion there might be no fall in saturation, while on another, with an identical blow, the saturation might fall by as much as 5 per cent. This finding could be explained by variations in the time in the cardiac cycle at which the intra-thoracic pressure was released. The pressure difference between the two atria varies during the cardiac cycle and, if the inflow of venous blood into the right atrium occurred at a time when the right atrial pressure was relatively high, the drop in saturation could be enhanced.

A different type of change in arterial oxygen saturation during Valsalva's manœuvre was seen in some patients with ASD in whom the pulmonary blood flow was only about twice the systemic flow. An example is shown in Fig. 6. The difference was that the saturation fell towards the end of the period of strain, instead of remaining raised until shunt reversal occurred. The fall in 
saturation after the intrathoracic pressure was released still occurred, in this case after two seconds. The fall in saturation during the latter part of the period of strain was the only feature distinguishing this type of tracing from that shown in Fig. 4. The suggested explanation for this fall in saturation is that the pulmonary flow was insufficient to maintain the left atrial pressure above the right throughout the period of strain: as a result some of the right atrial blood passed directly into the left atrium instead of via the right ventricle, lungs, and pulmonary veins. The chances of this happening would be increased if some systemic venous blood leaked into the right atrium from the venæ cavæ. There is evidence from angiocardiographic studies (Bolt et al., 1956) that Valsalva's manœuvre does

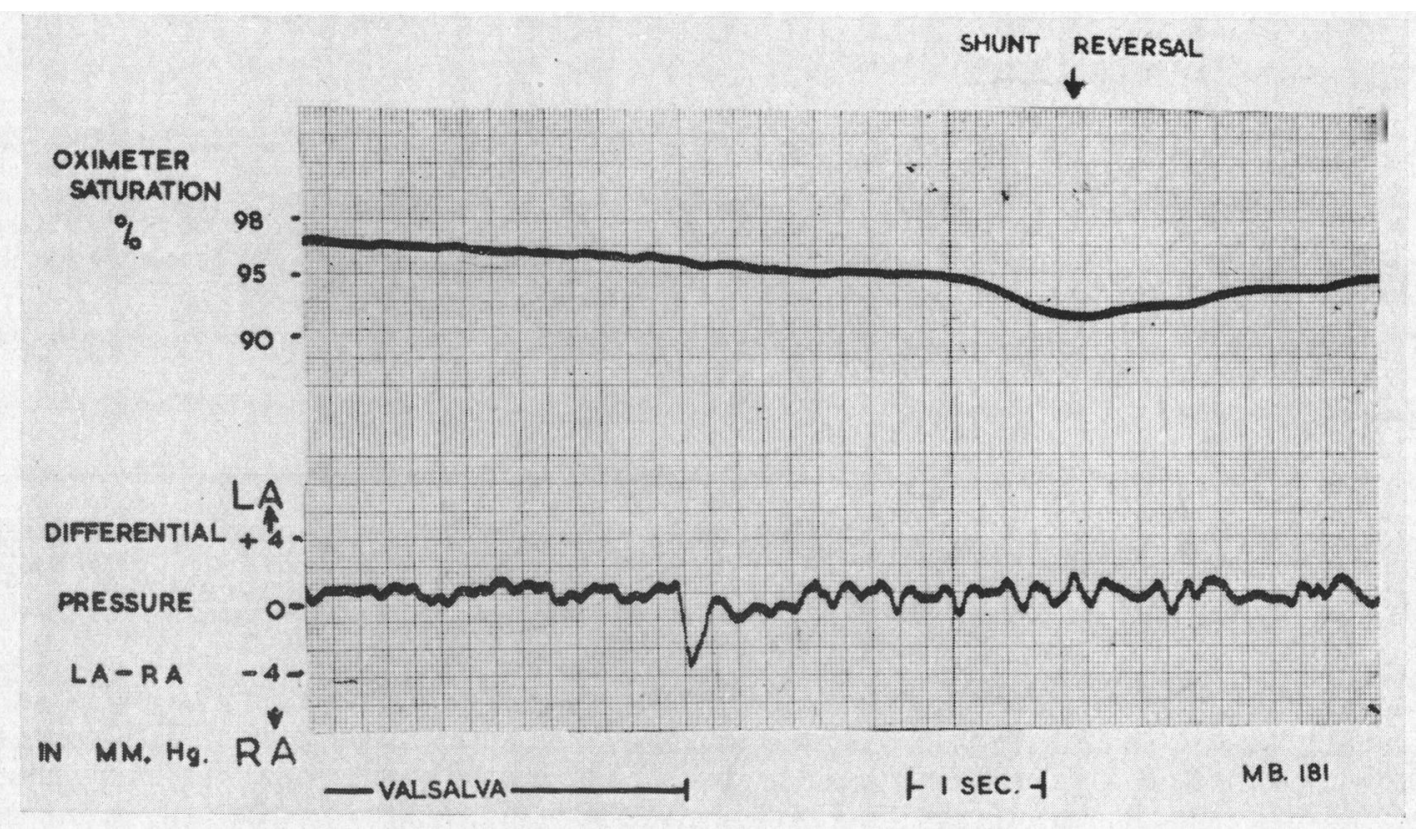

FIG. 5.-Differential pressure tracing between left and right atrium in a patient with atrial septal defect, showing rise in right atrial pressure causing shunt reversal.
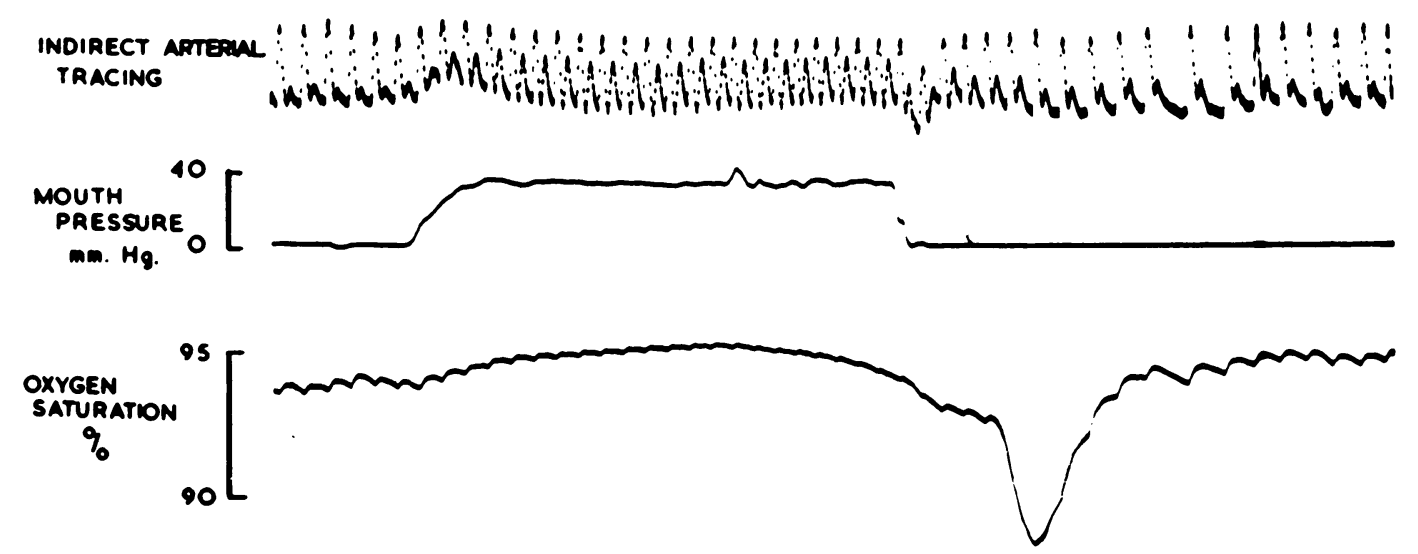

S. SEC

T. $\boldsymbol{w}$.

Fig. 6.-Shunt reversal after Valsalva's manœuvre in a patient with a small atrial septal defect. The arterial oxygen saturation falls before the end of the period of strain. 
not cut off the flow of blood from the inferior vena cava completely. Whatever the explanation of this fall in saturation during the period of strain, it only occurred in patients with a relatively low pulmonary blood flow. This point will be referred to later, when the results in cyanotic congenital heart disease are considered.

Shunt reversal could not be produced by Valsalva's manœuvre in all patients with ASD. If the arterial pressure response to Valsalva's manœuvre was "square wave" in type, shunt reversal did not occur. An example is shown in Fig. 7; in this symptom-free girl of 13, in whom the pulmonary

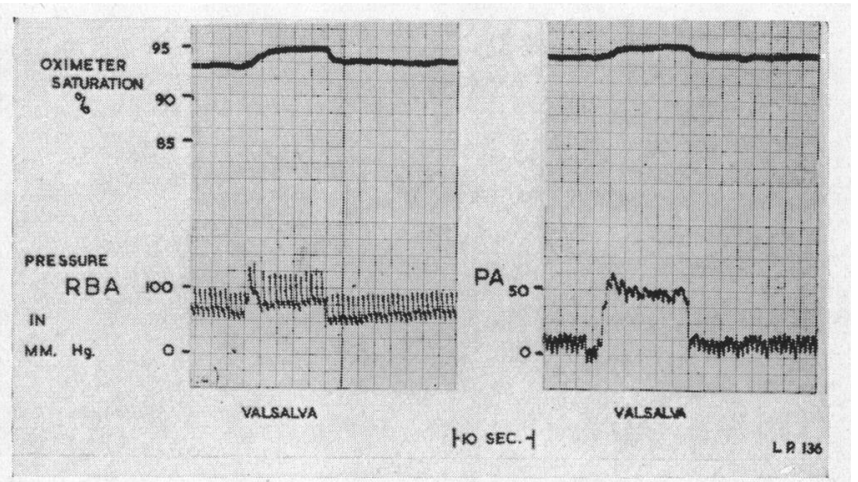

FIG. 7.-Square wave systemic and pulmonary arterial pressure response to Valsalva's manœuvre with no shunt reversal, in a patient with a large atrial septal defect.

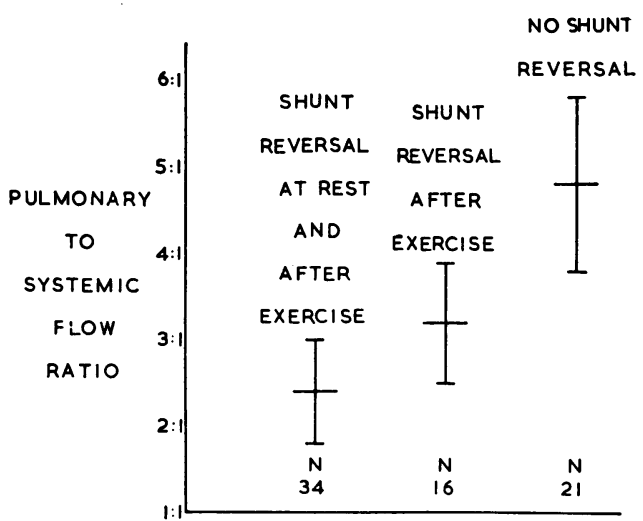

Fig. 8.-Pulmonary to systemic flow ratio in 71 patients with atrial septal defect, showing relationship between size of shunt and shunt reversal after Valsalva's manœuvre.

flow was more than four times the systemic flow, the response of both the systemic and pulmonary arterial pressures to Valsalva's manœuvre was square wave in type. There was no fall in pressure during the period of strain, no overshoot afterwards, and no change in pulse rate. This tracing was obtained during cardiac catheterization with the patient lying flat, and there was an artefactual rise in saturation during the period of strain. There was no evidence of shunt reversal after Valsalva's manœuvre, the saturation remaining unchanged in the period after the intra-thoracic pressure was released. The suggested explanation for the negative findings is that the heart and lungs did not empty during Valsalva's manœuvre, because there was sufficient blood recirculating through the lungs to keep both atria relatively full during the period of strain: the systemic arterial pressure was therefore maintained when the systemic venous return was cut off and, when the venous return was restored after 10 seconds, the inflow of venous blood was not sufficient to raise the right atrial pressure above the left, so that shunt reversal did not occur.

In some patients with ASD of moderate size, shunt reversal could only be demonstrated when Valsalva's manœuvre was repeated after exercise. This may have been because the systemic output increased on exercise, while the pulmonary flow remained relatively constant. Any increase in systemic flow would give the heart and lungs a better chance to empty during Valsalva's manœuvre and tend to convert a square wave response at rest to a normal response after exercise, enabling shunt reversal to occur.

The 71 patients with uncomplicated atrial septal defect studied have been divided into three groups on the basis of shunt reversal after Valsalva's manœuvre; (1) shunt reversal at rest and after exercise, (2) shunt reversal only after exercise, and (3) no shunt reversal at rest or after exercise. The difference in the size of the shunt in these three groups is shown in Fig. 8. In this graph the mean ratio between the pulmonary and systemic flows is shown for each group, together with the standard deviation. This ratio was thought to be the best measure of the size of the shunt and was calculated in a standard manner from the oxygen content of superior vena caval and pulmonary 
and systemic arterial blood, assuming the pulmonary venous blood to be 95 per cent saturated. This method tends to exaggerate the size of the shunt, but, as inferior vena caval and pulmonary venous samples were not obtained in every case, it was preferred to more accurate methods. The mean ratios in the three groups were $2 \cdot 4,3 \cdot 2$, and $4 \cdot 7$, indicating that, as the shunt increased, it became more and more difficult to reverse with Valsalva's manœuvre. It should be stressed that patients with odema of the ankles or a venous pressure over $5 \mathrm{~mm}$. $\mathrm{Hg}$ were excluded and the patients with a square wave Valsalva did not have heart failure. In four patients with ASD in heart failure, the response to Valsalva's manœuvre was square wave, no shunt reversal could be demonstrated, and the pulmonary to systemic flow ratio averaged $3 \cdot 2$.

In 33 patients studies were carried out three weeks to 18 months after repair of an ASD by direct suture under hypothermia; 13 of these had been studied before operation. In seven there was evidence of shunt reversal after operation, indicating that a defect was still present. In four there was some doubt whether the defect was closed, usually because the response to Valsalva's manœuvre was not certainly normal. In the other 22 patients, no shunt reversal could be demonstrated, the Valsalva was normal and the defect was thought to be closed. A number of the first cases to be treated surgically were included, so the group cannot be said to be representative. In all the patients studied before and after operation, the results indicated that the defect was smaller than before surgery. A tracing showing shunt reversal after operation is shown in Fig. 9.

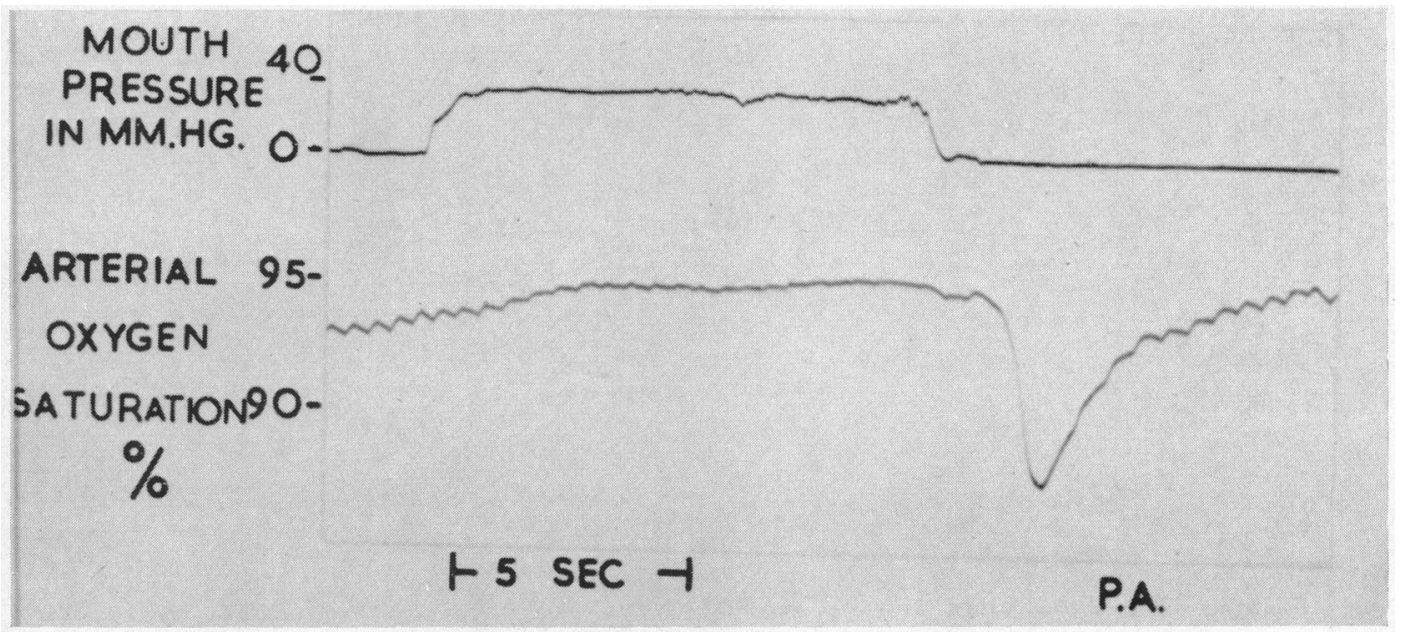

FIG. 9.-Shunt reversal after Valsalva's manœuvre after operation for closure of atrial septal defect.

In the patients with ASD discussed so far, the arterial oxygen saturation did not fall below 90 per cent on exercise; in a number, it rose on exercise. Eight patients were encountered in whom the saturation fell on exercise. Patients with pulmonary hypertension, pulmonary stenosis, Ebstein's disease, and reversed interatrial shunt with cyanosis at rest were not included in this group, all of whom had a raised pulmonary blood flow. Four were thought to have endocardial cushion defects, usually with a mitral systolic murmur and left axis deviation in the electrocardiogram. In these four the arterial oxygen saturation fell to 83-85 per cent after walking up four flights of stairs. Seven others with probable ostium primum defects were studied, but apart from one, who showed a fall in saturation after amyl nitrite inhalation, the findings were similar to those in patients with secundum defects. A possible explanation for the slight fall in arterial oxygen saturation on exercise could be a shunt from right atrium to left ventricle.

In two patients, with high ASD and anomalous pulmonary venous drainage into the superior vena cava, the saturation fell on exercise to 83 and 80 per cent. Eleven others with high defects 
and anomalous pulmonary venous drainage were studied and showed findings similar to those with secundum defects. The fall in saturation on exercise with high defects could be due to preferential shunting of superior vena cava blood into the left atrium and dye studies suggested that this occurred in one of the patients. In the other two, the saturation fell to 70 per cent on exercise and there was nothing to suggest that the ASD, which was proved by cardiac catheterization, was atypical. From these results, it would seem that a fall in arterial oxygen saturation on exercise, in a patient with an otherwise typical ASD, should suggest an ostium primum defect or a high defect with anomalous venous drainage, but that the absence of a fall in saturation on exercise is of no help in diagnosis. Lee and Gimlette (1957) have shown that it is possible to recognize the condition of anomalous venous drainage of the right lung into the right atrium with no atrial defect, by the failure to demonstrate shunt reversal after Valsalva's manœuvre. Only one patient was encountered in whom this diagnosis was possible and the catheter findings were unfortunately incomplete: surgical treatment was not undertaken, so that the diagnosis was not proved.

Ebstein's Anomaly. Three patients with Ebstein's anomaly were studied, and are included in this section because none of them were cyanosed at rest or after exercise. In one there was no evidence of a defect and no shunt reversal was demonstrated. The other two, only one of whom was catheterized, showed a different type of change in saturation with Valsalva's manœuvre from that seen in typical ASD. There was no change in saturation at rest and the arterial pressure response was square wave in type. The tracing obtained after exercise is shown in Fig. 10. The saturation fell throughout the period of strain, suggesting that in this case the right heart emptied directly through the defect. The only other patient in whom a similar tracing was obtained had an ASD with a normal pulmonary flow and shunt reversal on exercise for which no adequate cause could be found.

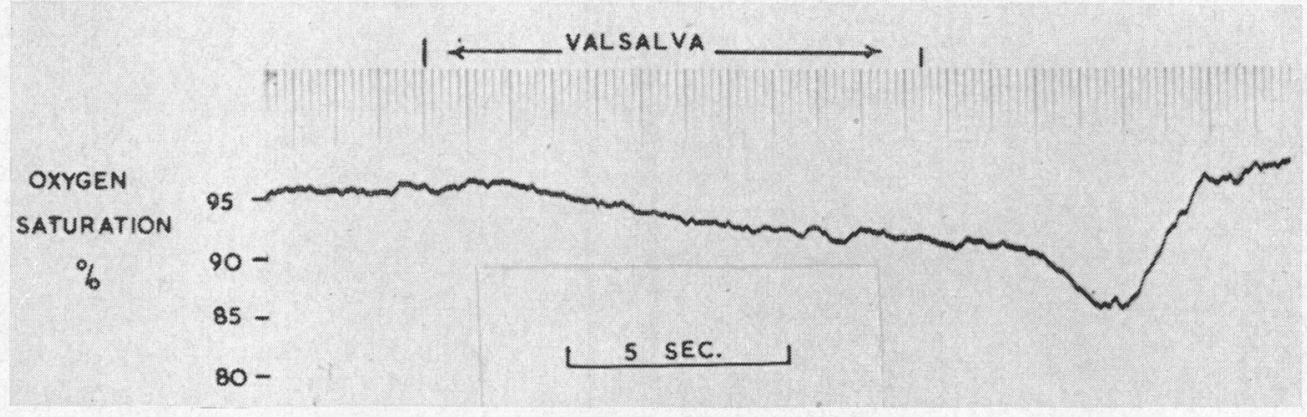

Fig. 10.-Fall in arterial oxygen saturation during and after Valsalva's manœuvre in a patient with Ebstein's anomaly.

\section{Ventricular Septal Defect and Patent Ductus Arteriosus}

Shunt reversal after Valsalva's manœuvre was not demonstrated in any patient with uncomplicated ventricular septal defect or patent ductus arteriosus. Presumably the pressure difference or shunt across such defects is sufficient to prevent shunt reversal. Only eight patients with ventricular septal defect and three with patent ductus were studied, because it became apparent that no useful information could be obtained. In three patients in whom the diagnosis of both atrial and ventricular septal defect was made, shunt reversal occurred. This was taken as evidence that an atrial defect was present, but as none of the three has died or come to operation, it is not certain whether the defects were separate or combined in a defect of the endocardial cushions.

\section{CYANOSIS ON EXERCISE}

In a number of patients, cyanosis was clinically detectable only after exercise. Oximetric confirmation of a fall in saturation was often useful in diagnosis. The patients in whom there was 
difficulty in the clinical assessment of cyanosis usually had either pulmonary stenosis or pulmonary hypertension with a low cardiac output and peripheral cyanosis. The finding of a fall in saturation on exercise ruled out isolated pulmonary stenosis or primary pulmonary hypertension. The commonest problem in such patients was the differentiation of mild or "acyanotic" Fallot's tetralogy from pulmonary stenosis with normal aortic root. While this distinction can readily be made in severe cases on clinical grounds, it may be difficult, even after cardiac catheterization, in milder cases. Twenty-six patients with pulmonary stenosis were studied, in whom the resting arterial oxygen saturation was 85 per cent or more. Of these, 13 were cases of Fallot's tetralogy, 8 had an atrial defect, 2 had a patent foramen ovale, and 3 had no defect at atrial or ventricular level. The right ventricular pressure varied between 70 and $135 \mathrm{~mm}$. $\mathrm{Hg}$ in the whole group, and even in the patients with Fallot's tetralogy, there was sometimes up to $40 \mathrm{~mm}$. $\mathrm{Hg}$ difference between right ventricular and systemic arterial pressures.

The results of oximetric studies are shown in Table I; the most distinctive feature in the patients with Fallot's tetralogy was that the arterial oxygen saturation fell precipitously on exercise. In the patients with normal aortic root, the fall was much less. This difference is shown in Fig. 2

TABLE I

Results in 26 Patients with Pulmonary Stenosis

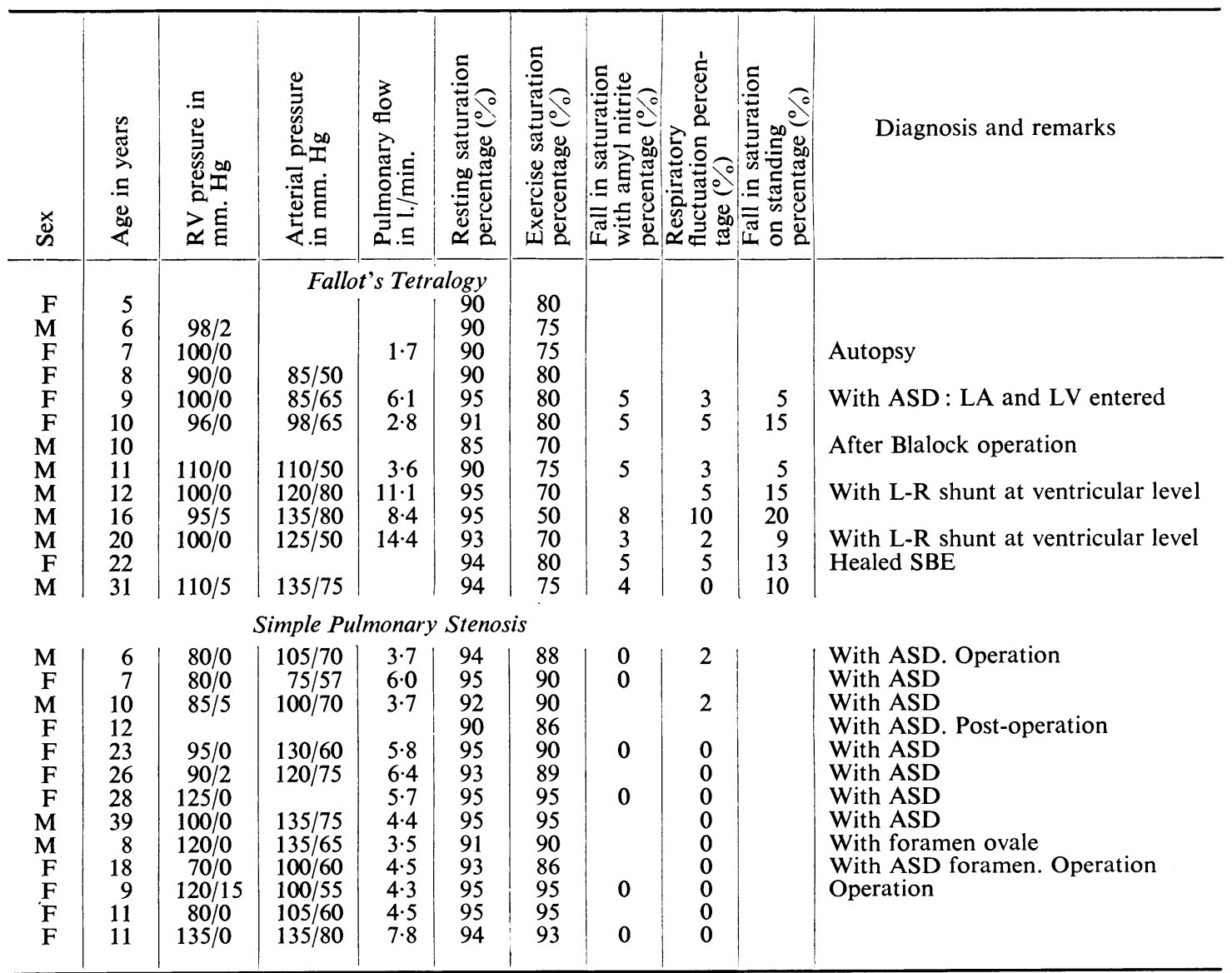

(p. 294), in which the arterial oxygen saturation has been plotted against the amount of exercise, measured by the number of flights of stairs climbed. The explanation for this difference probably 
lies in the fact that the right ventricle in Fallot's tetralogy is in direct communication with the systemic circulation and therefore the pulmonary flow cannot increase on exercise. The resistance to blood flow through the pulmonary stenosis does not alter on exercise and the right ventricular pressure, being necessarily the same as the left, cannot rise to force more blood through the lungs. As a result, the increased venous return during exercise is shunted through the ventricular septal defect into the systemic circulation. In pulmonary stenosis with normal aortic root, the right ventricular pressure can rise on exercise and increase the flow of blood to the lungs, and the arterial oxygen saturation does not fall on exercise, unless there is a reversed shunt through an ASD.

Another feature in patients with Fallot's tetralogy was that the arterial oxygen saturation fell 3-8 per cent after amyl nitrite inhalation. This did not occur in patients with a normal aortic root. The explanation is that amyl nitrite reduces the systemic resistance and, since in Fallot's tetralogy the right ventricle is in free communication with the systemic circulation during systole, the fall in systemic resistance results in an increase in the right-to-left shunt, producing a fall in arterial oxygen saturation. With an intact ventricular septum, it does not fall since the systemic circulation is not in direct communication with the right ventricle.

Respiratory fluctuations in the arterial oxygen saturation were greater in patients with Fallot's tetralogy, varying between 2 and 10 per cent after exercise, against 0-2 per cent in patients with normal aortic root and an atrial defect. The change in arterial oxygen saturation on squatting and standing after exercise was also striking in patients with Fallot's tetralogy, and an example is shown in Fig. 11. It should be emphasized that few of the patients squatted spontaneously. The possible explanations of the effect of squatting will be referred to later when the results in cyanotic patients are considered.

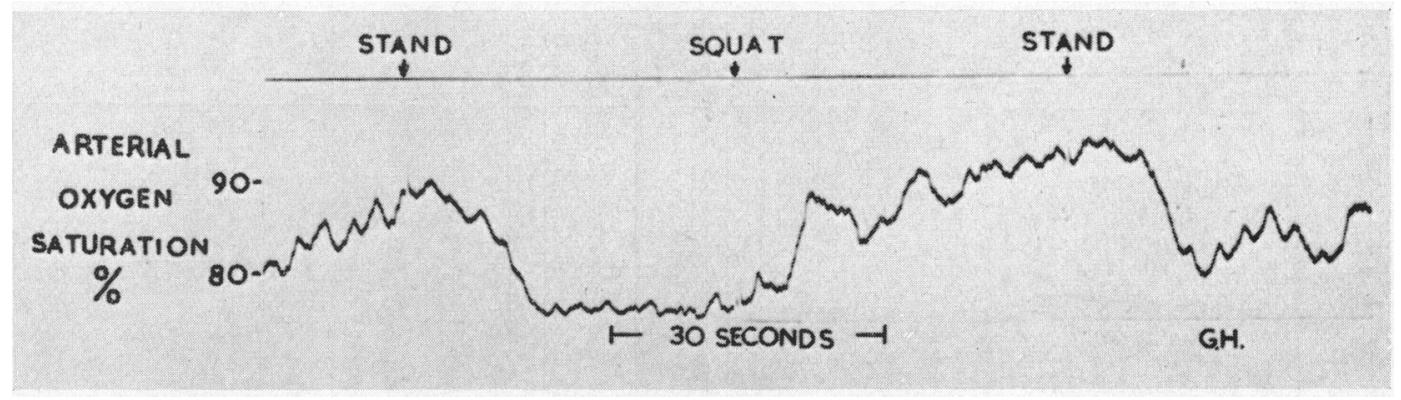

FIG. 11.-Fall in arterial oxygen saturation on standing up from the squatting position after exercise, and rise in saturation on squatting again, in a patient with Fallot's tetralogy.

\section{Patients with Cyanosis at Rest}

One of the important uses of oximetry is in distinguishing cyanosis due to a right-to-left shunt from cyanosis due to lung disease. This distinction can be made by measuring the effect of oxygen breathing on the arterial oxygen saturation. If there is cyanosis due to lung disease, the arterial saturation rises rapidly when the patient breathes pure oxygen, as shown in Fig. 12. In this patient with cor pulmonale, the initial saturation was 83 per cent and it rose rapidly, at a maximum rate of 33 per cent per minute, in an exponential manner to above 95 per cent. This tracing should be compared with that shown in Fig. 13, from a patient with pulmonary stenosis with reversed interatrial shunt. In this patient, the initial saturation was 70 per cent and with pure oxygen the saturation rose slowly and in a linear fashion at a rate of 2.5 per cent per minute to 75 per cent. Three patients with cyanosis due to lung disease and 20 patients with shunts were studied. The maximum rate of rise in the patients with lung disease averaged 27 per cent with pure oxygen and 7 per cent with 30 per cent oxygen. The patients with shunts can be divided into those in whom the shunt was purely right to left and those in whom it was bi-directional. In the former, the rise in saturation 


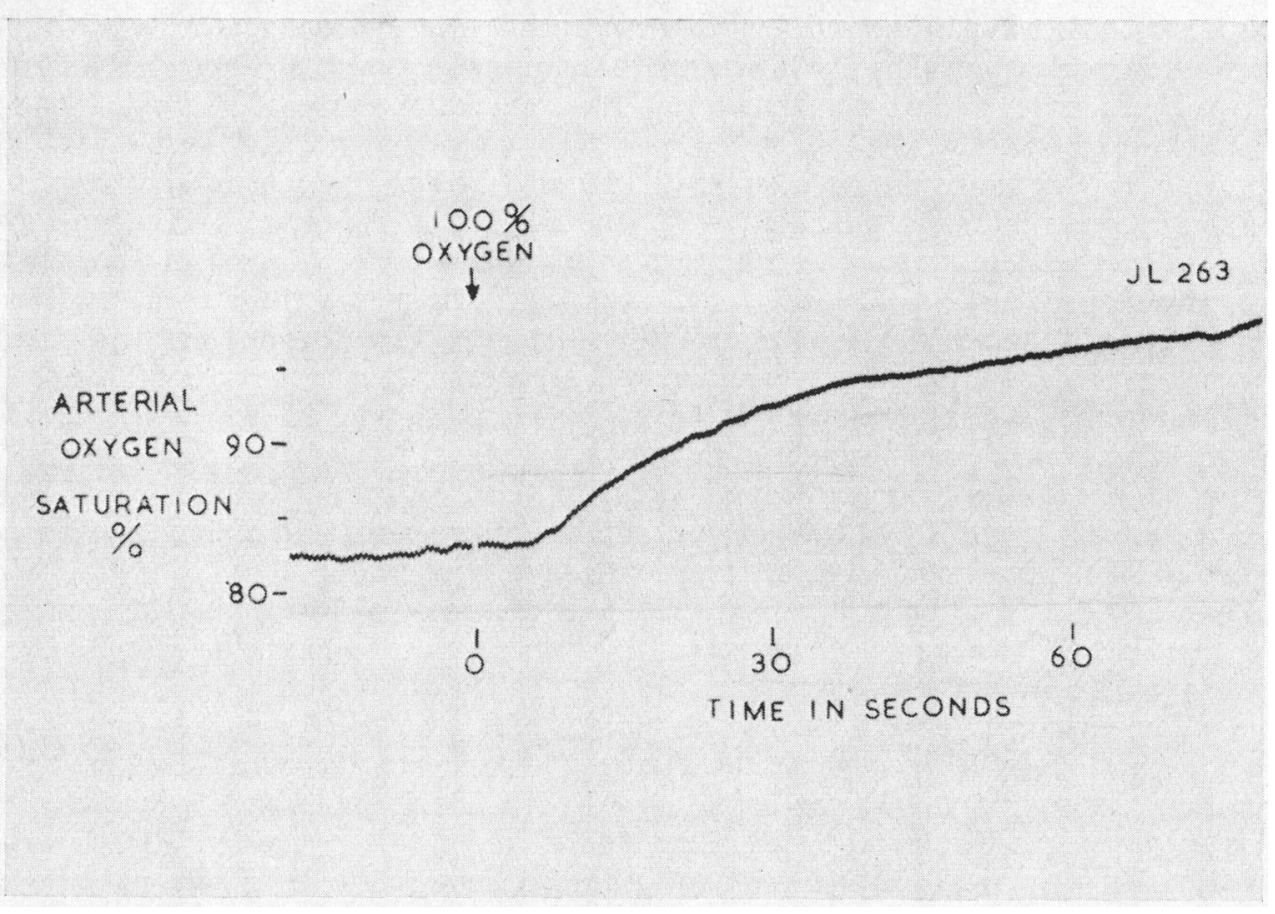

FIG. 12.-Rapid exponential rise in arterial oxygen saturation with oxygen breathing in a patient with cor pulmonale.

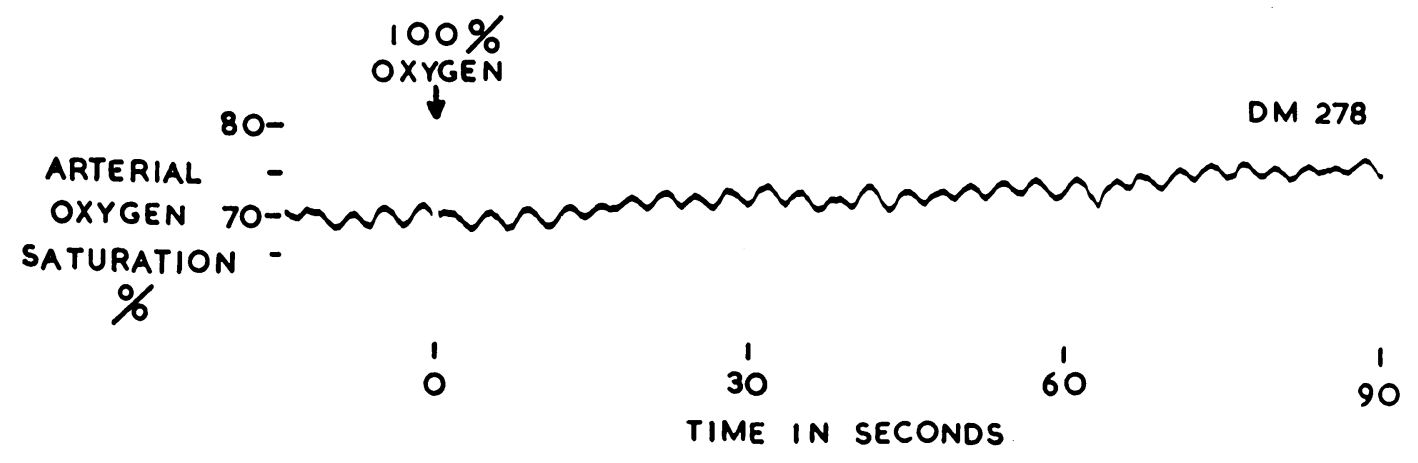

FIG. 13. - Slow linear rise in arterial oxygen saturation with oxygen breathing in a patient with pulmonary stenosis and reversed interatrial shunt. The fluctuations in saturation are respiratory.

averaged $3 \cdot 6$, against $2 \cdot 9$ per cent in the latter group. There was no significant rise in saturation with 30 per cent oxygen in patients with shunts.

The reason for the rapid rise in arterial oxygen saturation in patients with lung disease is the rapid rise in alveolar oxygen tension with oxygen breathing. In such patients, the blood leaving the lungs is not fully saturated with oxygen, because diffusion of oxygen from the alveolar air into the pulmonary capillary blood is impaired. Any increase in alveolar oxygen tension increases the rate of diffusion of oxygen. With 30 per cent oxygen, the pressure of oxygen causing diffusion across the pulmonary membrane is about doubled and with pure oxygen it is increased more than sixfold, so that any impairment of diffusion is rapidly corrected. In practice, the rate at which the arterial 
oxygen saturation rises in patients with lung disease depends on the rate at which the inspired oxygen mixes with the alveolar air. The rise in saturation is alinear because it depends on the relationship between oxygen tension and oxygen saturation-the dissociation curve of hæmoglobin-which is alinear in its upper range.

In patients with cyanosis due to a shunt, the blood leaves the lungs normally saturated with oxygen, and cyanosis is due to the addition of venous blood in the heart. When such a patient breathes pure oxygen, the amount of oxygen in solution in the blood increases from the normal value of $3 \mathrm{ml}$./1. to $20 \mathrm{ml}$./1. (Comroe and Dripps, 1950), because extra oxygen dissolves in the plasma in proportion to the rise in alveolar oxygen tension. The extra oxygen in solution in the pulmonary venous blood is available to combine with unsaturated hæmoglobin in the shunted blood and raise the arterial oxygen saturation. If the pulmonary and systemic flows remain the same with oxygen breathing, a new equilibrium is eventually reached, with the systemic arterial and venous and the pulmonary venous bloods all containing $17 \mathrm{ml}$./1. more oxygen than before. The rate at which this new equilibrium is reached depends on the relative amounts of pulmonary and systemic blood flow. The rise in arterial oxygen saturation is slow, because only $17 \mathrm{ml}$. of extra oxygen can be carried in every litre of blood; it is relatively linear because each extra ml. of oxygen produces the same rise in arterial oxygen saturation and the process does not depend on the relationship between oxygen tension and oxygen saturation.

If the pulmonary or systemic flow alters as a result of oxygen breathing, the situation becomes more complex and superficially may resemble that seen in patients with cyanosis due to lung disease, the saturation rising rapidly. Oxygen breathing may occasionally reduce the pulmonary vascular resistance in patients with a right-to-left shunt and pulmonary hypertension. In this case, the arterial saturation may rise, because less blood is shunted from right to left. The rate at which the saturation rises must depend on the rate at which the pulmonary vascular resistance changes. Only one patient was encountered in whom this state of affairs was thought to exist, and a tracing of the brachial and pulmonary arterial pressures and arterial oxygen saturation are shown in Fig. 14. The woman had an ASD with pulmonary hypertension, which apparently followed pregnancy,

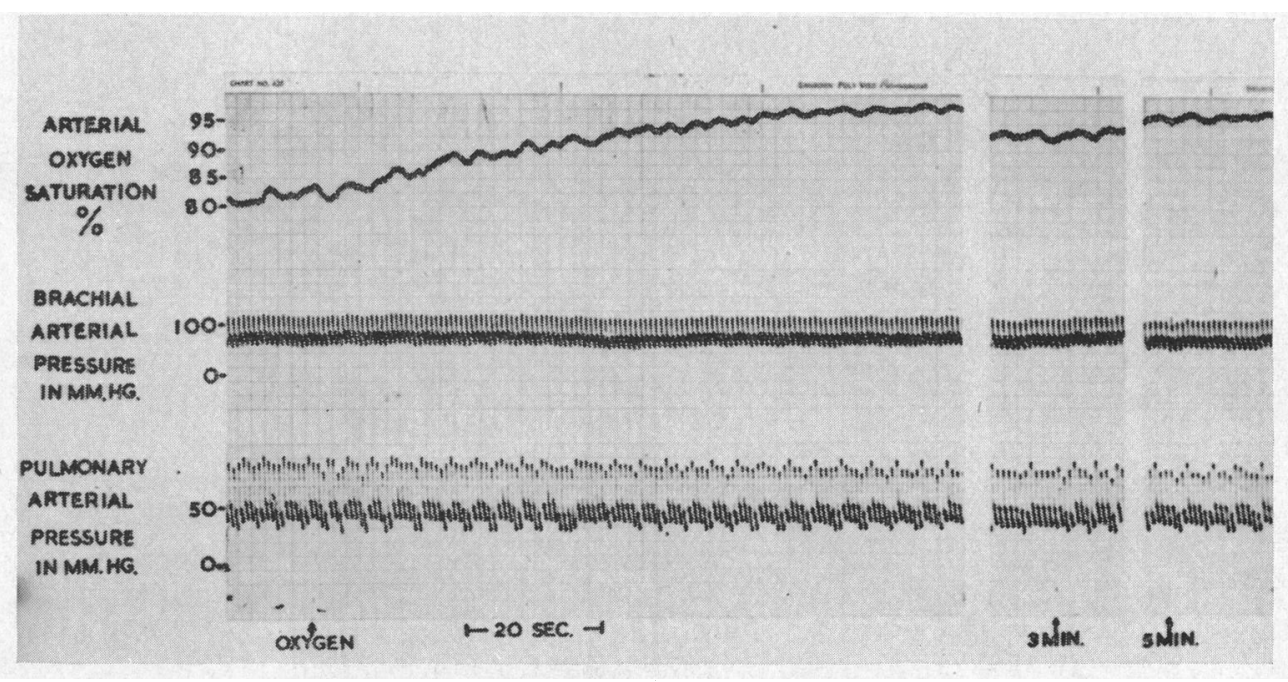

FIG. 14.-Tracing of arterial oxygen saturation and brachial and pulmonary arterial pressures, showing a rise in saturation and slight fall in pulmonary arterial pressure with oxygen breathing, in a patient with atrial septal defect and pulmonary hypertension. The oximeter was rebalanced after two minutes.

cyanosis being first noticed about the age of 25 years. Her diffusing capacity at rest and on exercise was normal, so that there was no question of impaired pulmonary function. It will 
be seen from Fig. 14 that the arterial oxygen saturation rose at a rate of more than 15 per cent per minute and the pulmonary arterial pressure fell from $80 / 40$ to $70 / 30 \mathrm{~mm}$. Similar falls in pulmonary arterial pressure were found in two patients with cor pulmonale and pulmonary hypertension, in whom the pulmonary vascular resistance fell with oxygen breathing and in another with ASD and pulmonary hypertension, the arterial oxygen saturation rose at a rate of 27 per cent per minute, but in these three the diffusing capacity was abnormally low. In four other patients with pulmonary hypertension and a right-to-left shunt, the pulmonary vascular resistance did not alter with oxygen breathing and the rise in arterial saturation was compatible with increased transport of oxygen in solution in the plasma. These findings indicate that a rapid rise in arterial oxygen saturation with pure oxygen, of 10 per cent per minute or more, is evidence of impaired diffusion or of a change in the pulmonary vascular resistance with oxygen breathing. The distinction between these two factors can only be inferred from measurement of the diffusing capacity of the lungs.

\section{Calculation of Pulmonary and Systemic Blood Flow}

The factors involved in the increase in arterial oxygen saturation with oxygen breathing in patients with a right-to-left shunt are such that it is possible to calculate the relative amounts of pulmonary and systemic flow, if certain assumptions are made. If the initial arterial saturation and the oxygen consumption are also known, the actual flows can be calculated.

The calculation is based on the measurement of the rate of linear rise in arterial oxygen saturation in the arbitrary period between $\frac{1}{2}$ and $1 \frac{1}{2}$ minutes after the patient starts to breathe pure oxygen. This gives an indication of the rate at which oxygen is being added to the blood reaching the systemic circulation. The extra oxygen has been carried in the pulmonary venous blood in known concentration, so that the relationship between the pulmonary and systemic flows can be calculated.

The necessary assumption involved are as follows.

(1) That the shunt is solely from right to left.

(2) That gas mixing in the lungs is virtually complete within 30 seconds of starting to breathe pure oxygen.

(3) That breathing pure oxygen does not alter the pulmonary or systemic blood flow.

(4) That the pulmonary venous blood is normally saturated with oxygen.

(5) That the amount of oxygen in solution increases by $17 \mathrm{ml}$. per litre when the subject breathes pure oxygen.

(6) That the time taken for the mixed venous blood to reach equilibrium, with an oxygen content $17 \mathrm{ml} / \mathrm{l}$. above its initial level, is more than two minutes.

Calculation. Let $x=$ pulmonary blood flow in 1./min., and $y=$ systemic blood flow in $1 . / \mathrm{min}$.

Then if assumption (1) is correct, $y-x=$ shunt flow in $1 . / \mathrm{min}$.

Let $C=$ oxygen capacity of blood in ml./l., and $a=$ linear rise in arterial oxygen saturation in per cent per min.

Then if $17 \mathrm{ml}$. of extra oxygen dissolve in each litre of pulmonary flow when the patient breathes pure oxygen, the rate at which extra oxygen reaches the left heart is $17 x \mathrm{ml} . / \mathrm{min}$.

The rate at which extra oxygen appears in the systemic arterial blood in $\mathrm{ml} / \mathrm{min}$. depends on the rate of rise in saturation with oxygen and the oxygen capacity and is $\frac{a C y}{100} \mathrm{ml} / \mathrm{min}$.

If there is only a right-to-left shunt, these two rates should be equal:

or

$$
\begin{aligned}
\therefore 17 x & =\frac{a C y}{100} \\
\frac{y}{x} & =\frac{1700}{a C} .
\end{aligned}
$$

In patients with a right-to-left shunt, the arterial oxygen saturation depends on the mixing of systemic venous and pulmonary venous blood.

Let $V=$ mixed systemic venous oxygen saturation percentage.

$A=$ initial arterial oxygen saturation percentage. 
Then assuming a pulmonary venous oxygen saturation of 95 per cent.

or

$$
\begin{aligned}
A y & =V(y-x)+95 x \\
\frac{y}{x} & =\frac{95-V}{A-V} . .
\end{aligned}
$$

From equations (1) and (2):

$$
\begin{aligned}
\frac{1700}{a C} & =\frac{95-V}{A-V} \\
V & =\frac{1700 A-95 a C}{1700-a C}
\end{aligned}
$$
ciple.

If the oxygen uptake is known, the pulmonary and systemic flows can be calculated using the Fick prin-

Results. The pulmonary and systemic blood flows were calculated by this method and compared with

\begin{tabular}{|c|c|c|c|c|c|c|c|c|c|c|c|}
\hline \multirow[b]{2}{*}{ ڤ゙્ } & \multirow[b]{2}{*}{ 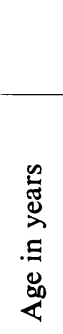 } & \multirow[b]{2}{*}{ 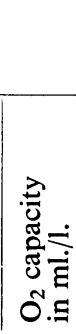 } & \multirow[b]{2}{*}{ 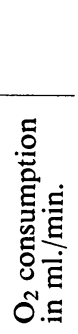 } & \multicolumn{4}{|c|}{$\begin{array}{l}\text { Measured at } \\
\text { catheterization }\end{array}$} & \multicolumn{3}{|c|}{$\begin{array}{l}\text { Calculated from } \\
\text { oximetry }\end{array}$} & \multirow[b]{2}{*}{ Diagnosis and remarks } \\
\hline & & & & 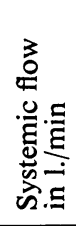 & 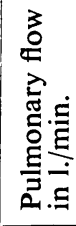 & 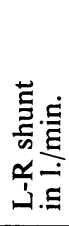 & 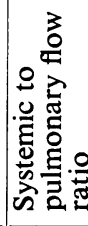 & 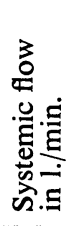 & 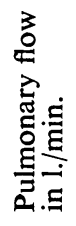 & 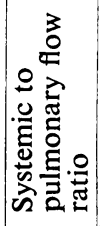 & \\
\hline $\mathbf{M}$ & 10 & 308 & 246 & 6.0 & 1.4 & 0 & $4 \cdot 3$ & $6 \cdot 3$ & $2 \cdot 0$ & $3 \cdot 2$ & Fallot's tetralogy \\
\hline $\mathbf{F}$ & 25 & 246 & 201 & $14 \cdot 0$ & $2 \cdot 0$ & 0 & 7.0 & 6.8 & 1.9 & 3.5 & Fallot's tetralogy: autopsy \\
\hline $\mathrm{F}$ & 9 & 259 & 192 & $3 \cdot 5$ & $2 \cdot 0$ & 0 & 1.8 & 6.5 & $3 \cdot 2$ & 2.0 & Pulm. stenosis with rev. I-A shunt \\
\hline M & 40 & 296 & 250 & 4.5 & $2 \cdot 3$ & 0 & 2.0 & 1.8 & 1.2 & 1.5 & Pulm. atresia: operation \\
\hline $\mathbf{M}$ & 17 & 304 & $250^{*}$ & $5 \cdot 6$ & $1 \cdot 7$ & 0 & $3 \cdot 3$ & $4 \cdot 2$ & 1.5 & 2.6 & Tricuspid atresia \\
\hline $\mathbf{F}$ & 31 & 215 & 230 & 4.9 & $2 \cdot 1$ & 0 & $2 \cdot 3$ & 9.0 & 4.0 & $2 \cdot 3$ & Pulm. hypertension: A-V communis \\
\hline $\mathbf{F}$ & 57 & 249 & 167 & 2.5 & $1 \cdot 3$ & 0 & 1.9 & 4.5 & $2 \cdot 5$ & 1.8 & Pulm. hypertension: VSD \\
\hline $\mathrm{F}$ & 22 & 198 & 271 & $5 \cdot 3$ & $3 \cdot 4$ & $1 \cdot 2$ & 1.6 & 11.5 & 3.6 & $3 \cdot 2$ & Pulm. hypertension: PDA + VSD \\
\hline $\mathbf{M}$ & 36 & 292 & 311 & 6.0 & 3.0 & $1 \cdot 1$ & 2.0 & $4 \cdot 4$ & $2 \cdot 7$ & 1.6 & Pulm. hypertension: PDA + VSD \\
\hline $\mathbf{M}$ & 32 & 314 & 24 & 3.0 & $2 \cdot 5$ & $1 \cdot 1$ & $1 \cdot 2$ & $8 \cdot 7$ & $2 \cdot 7$ & $3 \cdot 2$ & Pulm. hypertension: ?A-V communis \\
\hline $\mathrm{F}$ & 27 & 196 & $250^{*}$ & $2 \cdot 9$ & $3 \cdot 2$ & 0.8 & 0.9 & $13 \cdot 0$ & $6 \cdot 4$ & $2 \cdot 0$ & Pulm. hypertension: ASD \\
\hline $\mathbf{M}$ & 45 & 220 & & $5 \cdot 4$ & 4.5 & 0.3 & $1 \cdot 2$ & $15 \cdot 7$ & 6.8 & $2 \cdot 3$ & Pulm. hypertension: ASD \\
\hline $\mathrm{F}$ & 7 & 216 & $250^{*}$ & $2 \cdot 6$ & $10 \cdot 0$ & 8.0 & 0.3 & $7 \cdot 7$ & 6.7 & $1 \cdot 1$ & Transposition + pulm. stenosis \\
\hline $\mathrm{F}$ & 13 & 244 & 175 & $2 \cdot 3$ & $1 \cdot 8$ & 0.2 & $1 \cdot 8$ & $16 \cdot 0$ & $3 \cdot 7$ & $4 \cdot 3$ & Transposition + pulm. stenosis \\
\hline $\mathbf{M}$ & 32 & 263 & 255 & 4.0 & 3.8 & $1 \cdot 3$ & $1 \cdot 1$ & $1 \cdot 3$ & 1.0 & $1 \cdot 3$ & Reversed interatrial shunt \\
\hline
\end{tabular}
measurements obtained at catheterization in 15 patients. The results are shown in Table II. In seven

TABLE II

Comparison of Flows Measured at Catheterization and by Oximetry

* Assumed

patients with a right-to-left shunt, the agreement between the systemic to pulmonary flow ratios measured by the two methods was reasonably good, considering the possible errors involved. In eight patients, in whom the shunt was bi-directional, the agreement was poor, particularly when the left-to-right shunt was large as in one of the patients with transposition. This result was to be expected because the first assumption made was that the shunt was solely right to left. Because there was a left-to-right shunt, a proportion of the pulmonary venous blood, containing extra oxygen in solution, was shunted back to the lungs, so that the rise in arterial oxygen saturation was slower than it would have been if there had been a pure right-to-left shunt.

A better idea of the factors involved in this method of determining the cardiac output can be obtained by considering the relationship between the different variables. Fig. 15 shows a graph in which the systemic flow has been plotted against the initial arterial oxygen saturation with isopleths of different rates of change in oxygen saturation indicated. This graph is for the special case of an oxygen capacity of $200 \mathrm{ml} . / \mathrm{l}$. , a pulmonary venous saturation of 95 per cent, and an oxygen consumption of $250 \mathrm{ml} . / \mathrm{min}$. It will be seen 


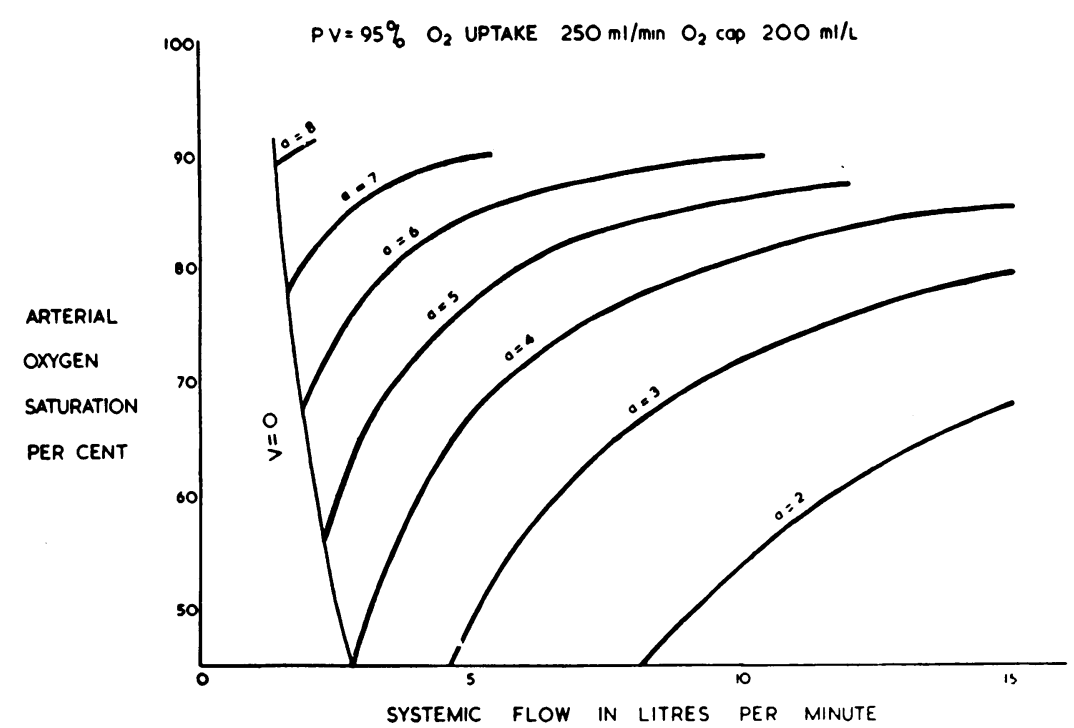

FIG. 15.-Theoretical graph of systemic flow and arterial oxygen saturation with isopleths of rate of change in arterial oxygen saturation with oxygen breathing (a). Line $\mathrm{V}=\mathrm{O}$ represents a mixed oxygen saturation of 0 per cent.

from this theoretical graph that, for a given initial arterial oxygen saturation, only small variations in the rate of rise of saturation are possible. The maximum rate is limited by the line indicating a mixed venous saturation of 0 per cent and the minimum by the systemic flow becoming ridiculously high. In general, a low arterial saturation implies a slow rise in saturation and a rapid rise in saturation tends to occur when the systemic flow is small. If the measured rise in saturation falls outside the theoretical limits set by such a graph, one of the assumptions must be wrong. If the rate of rise is too rapid, either there is lung disease and the blood leaving the lungs is unsaturated, or the pulmonary vascular resistance has fallen with oxygen breathing. If the rate of rise is too slow, it may be inferred that there is either a bi-directional shunt or that the mixing in the lungs is incomplete in 30 seconds.

The accuracy of the results calculated by this method is naturally not very great, because, as can be seen from Fig. 15, a small error in the measurement of the rate of rise in saturation must have a large effect on the calculated flow. The procedure is, however, simple and can easily be repeated without discomfort to the patient, so that it may well prove to be useful in following patients with Fallot's tetralogy and assessing the results of surgery. It could be used in steady state exercise and should be practicable in infants, where it might be useful in distinguishing a pure right-to-left shunt in Fallot's tetralogy from a bi-directional shunt in transposition.

\section{VAlSalva's ManæeuVRe}

The effect of Valsalva's manœuvre on the arterial oxygen saturation in patients with cyanotic congenital heart disease is considerable, a change of up to 25 per cent being occasionally seen. Two main patterns of change can be distinguished; these will be referred to as Type A and Type B, and are shown in Figs. 16 and 17. The principal difference was that in Type $A$ the saturation fell during the latter part of the period of strain, while in Type B, the saturation remained raised until the intrathoracic pressure was released. In both types of response there was usually an initial fall in saturation due to the inspiration preceding the period of strain and a fall in saturation 3-6 seconds after pressure was released, due to a right-to-left shunt associated with the resumption of venous return to the right heart.

Type A response was commonly found in patients with a ventricular septal defect, i.e. in Fallot's tetralogy and Eisenmenger's complex. It was originally thought to be diagnostic of a right-to-left shunt at ventricular level (McIlroy, 1958), but further studies have shown that it can occur in patients with an atrial defect. It is now thought that this response is analogous to that seen in patients with ASD in whom the pulmonary blood flow is small (Fig. 6), and depends on the size of the pulmonary flow, rather than the site of the defect. The evidence that the type of response was related to the pulmonary flow and not the site of the defect was 
that, in five patients with mild Fallot's tetralogy and in two with endocardinal cushion defects and pulmonary hypertension, there was a Type $B$ response at rest and a Type A response after exercise. An example is shown in Fig. 18 from a patient with an endocardial cushion defect and pulmonary hypertension.

The suggested explanation for the sequence of events in the Type A response is that, when the intrathoracic pressure is raised at the start of the period of strain, the systemic venous return is cut off and the

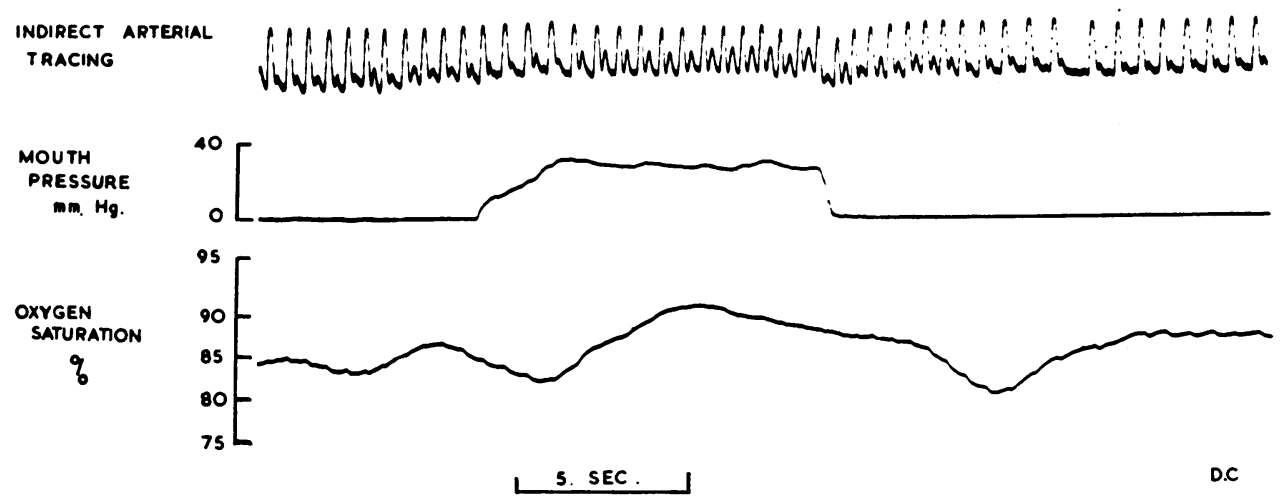

Fig. 16.-Type A response of arterial oxygen saturation to Valsalva's manœuvre, showing a fall in saturation during the period of strain.

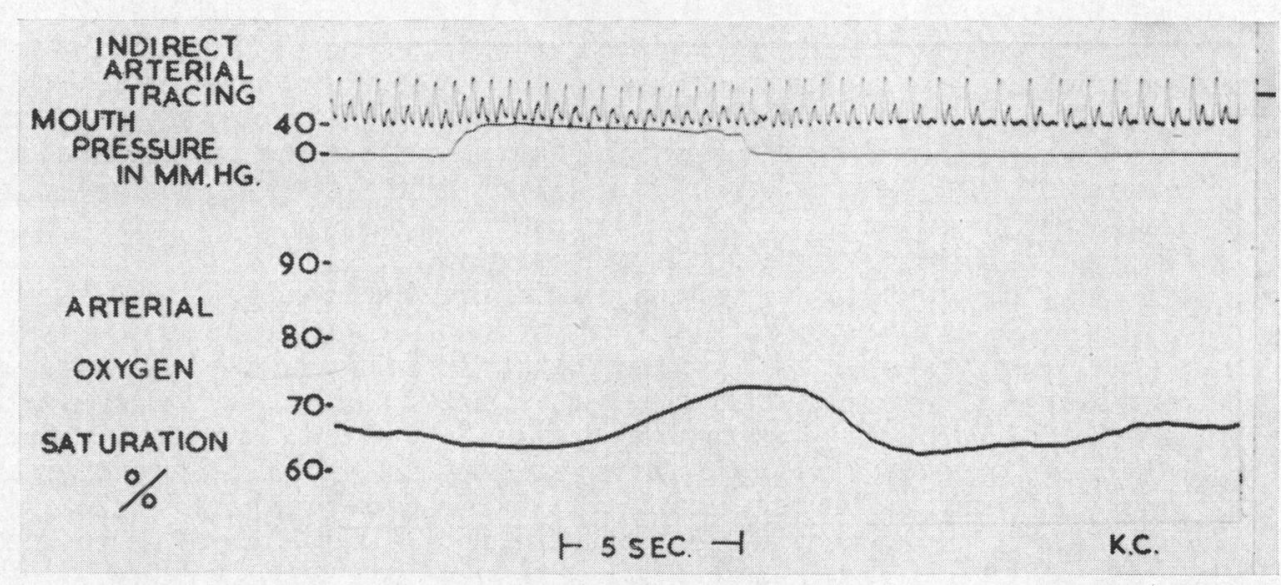

FIG. 17.-Type B response of arterial oxygen saturation to Valsalva's manœuvre, showing no fall in saturation until after the period of strain.

right-to-left shunt is reduced. If the pulmonary blood flow is small compared with the systemic, the lungs soon empty into the left heart and the left heart pressure tends to fall. The right heart then starts to empty through the defect, instead of through the pulmonary artery and lungs and the arterial saturation falls. The smaller the pulmonary blood flow, in relation to the systemic, the more likely will the heart be to empty in this way. If the patient exercises and increases the systemic flow, while keeping the pulmonary flow more or less constant, a Type A response will be more likely to occur. Another way of looking at this response is to think of Valsalva's manœuvre as an exaggerated expiration, squeezing blood out of the lungs into the left heart. If there is only a small amount of blood in the lungs, the resulting rise in arterial saturation will be short lived and right heart blood will soon start to flow across the defect again, producing a fall in arterial saturation.

Type B was always found in patients with a reversed shunt through a patent ductus and tricuspid or pulmonary atresia and should theoretically occur in persistent truncus arteriosus. It was also found in 


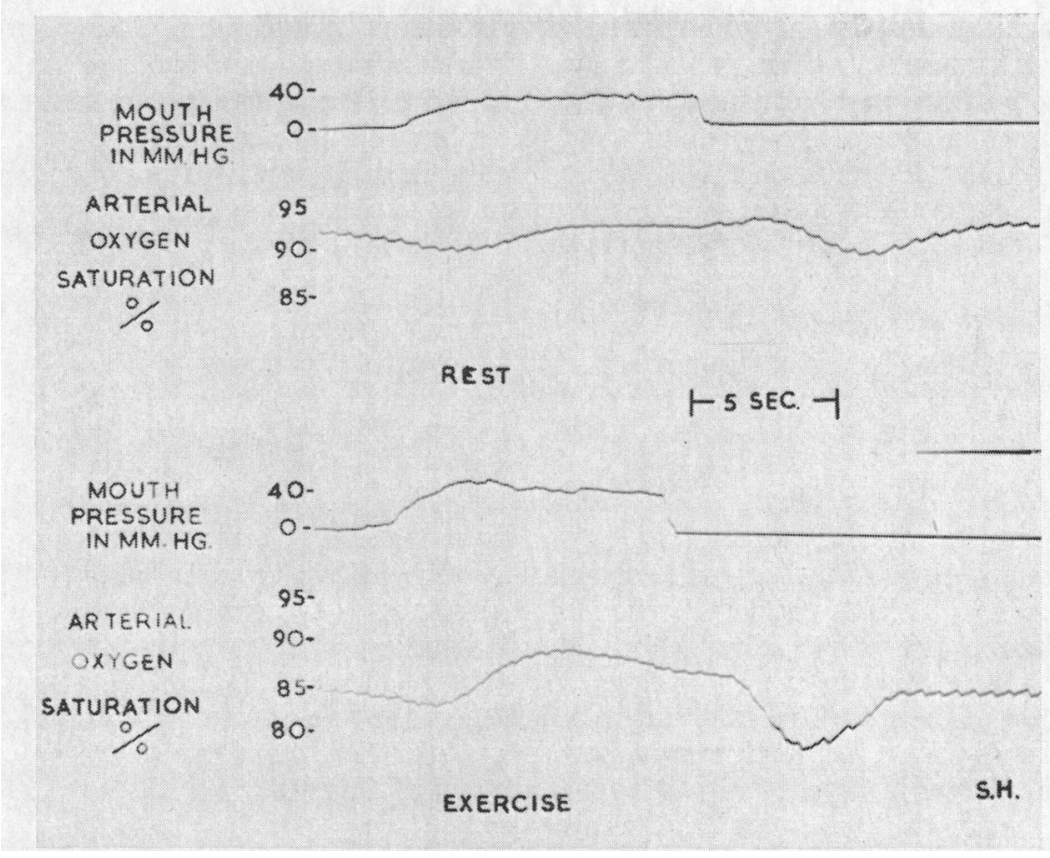

FIG. 18.-Type B response of arterial oxygen saturation to Valsalva's manœuvre at rest, and Type $\mathrm{A}$ response after exercise, in a patient with endocardial cushion defect and pulmonary hypertension.

patients with a reversed shunt at atrial or ventricular level, in whom the pulmonary flow was not reduced, and in cyanotic patients in whom the arterial pressure response to Valsalva's manœuvre was square wave in type. The suggested explanation of Type B response in patients with an aorta-pulmonary shunt is that the right heart cannot empty directly into the left, so that the saturation cannot fall during the period of strain. The flow of blood from the aorta to pulmonary artery can be maintained throughout the period of strain, because there is a circulation from the aorta to the pulmonary artery, then via the lungs to the left heart and back to the aorta. When the venous return to the right heart is cut off, the saturation rises because the right-toleft shunt is cut off; the right heart cannot empty into the aorta because the left-to-right shunt from the aorta to pulmonary artery can be maintained by the blood recirculating through the lungs. In pulmonary atresia and persistent truncus arteriosus the situation is slightly different, but the supply of blood to the lungs, coming directly off the aorta, cannot be cut off during the period of strain, because both sides of the heart must empty together. In tricuspid atresia, if the lungs are supplied via an atrial and ventricular septal defect, the right atrium must always empty through the atrial defect and blood flow to the lungs must be maintained via the ventricular septal defect throughout the period of strain. In patients with atrial or ventricular septal defects, in whom the pulmonary blood flow is sufficient to maintain a flow of pulmonary venous blood into the left heart throughout the period of strain, the right heart will continue to empty through the lungs and emptying through the defect will be prevented. As a result, the arterial saturation will not fall during Valsalva's manœuvre and a Type B response will occur. This state of affairs will be more likely to occur in patients with ASD, because the pulmonary blood flow tends to be higher. If the arterial pressure response to Valsalva's manœuvre is "square wave ", Type B response must occur because the heart does not empty.

From these speculations about the mechanisms involved in the changes in arterial oxygen saturation with Valsalva's manœuvre in different conditions it will be seen that the problem is difficult and the explanations put forward may well have to be modified in the light of further studies. Certain points do, however, seem to be established.

(1) Type A response can occur in ASD and is not diagnostic of ventricular septal defect.

(2) The type of response depends as much on the relative amounts of systemic and pulmonary flow as on the site of the defect.

(3) Type A response entails a normal arterial pressure response to Valsalva's manœuvre.

(4) If there is a square wave arterial response, the change in saturation will be Type B. 
The timing and extent of the changes in arterial oxygen saturation, during and after Valsalva's manœuvre in cyanotic patients, varied considerably. The situation is in some ways analogous to that found with dye studies in patients with right-to-left shunts. When the intrathoracic pressure is released after Valsalva's manœuvre a quantity of venous blood enters the right atrium in a bolus equivalent to an injection of dye. This venous blood reaches the ear via a right-to-left shunt in the same way as an injected dose of dye. If the circulation time is short the appearance time is short and, as venous blood tends to remain in a bolus, the drop in arterial saturation is sharp and short lived. If the heart-to-ear circulation time is prolonged, the drop in saturation tends to be less steep and spread over a longer time. The site of the shunt also appears to influence the shape and timing of the fall in saturation after Valsalva's manœuvre, a more delayed and spread out fall in saturation being seen when the shunt was aorto-pulmonary level. This may have been due to the bolus of venous blood becoming more spread out during its longer passage through the right heart.

\section{Amyl Nitrite Inhalation}

The effect of amyl nitrite inhalation on the arterial oxygen saturation was used to determine whether the right and left ventricles or aorta and pulmonary artery were in free communication. The use of amyl nitrite in distinguishing Fallot's tetralogy from pulmonary stenosis with normal aortic root has already been described. Similar results were obtained in cyanotic cases and in patients with pulmonary hypertension and an intracardiac shunt. More convincing tracings were obtained if intracardiac and systemic arterial pressures were also recorded as shown in Fig. 19, but a record of the pulse rate and arterial saturation was generally sufficient. In some patients with pulmonary hypertension and ASD it was found that amyl nitrite produced a rise in arterial saturation (Fig. 20) suggesting that amyl nitrite may have caused the pulmonary vascular resistance to fall, as much, if not more than the systemic.

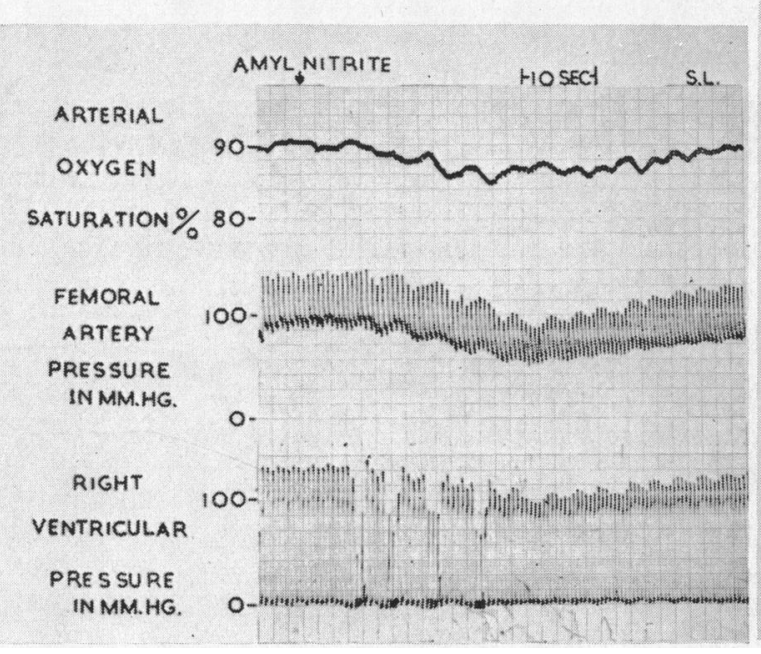

FIG. 19.-Fall in arterial oxygen saturation and femoral arterial and right ventricular pressures after amyl nitrite inhalation, in a patient with endocardial cushion defect and pulmonary hypertension.

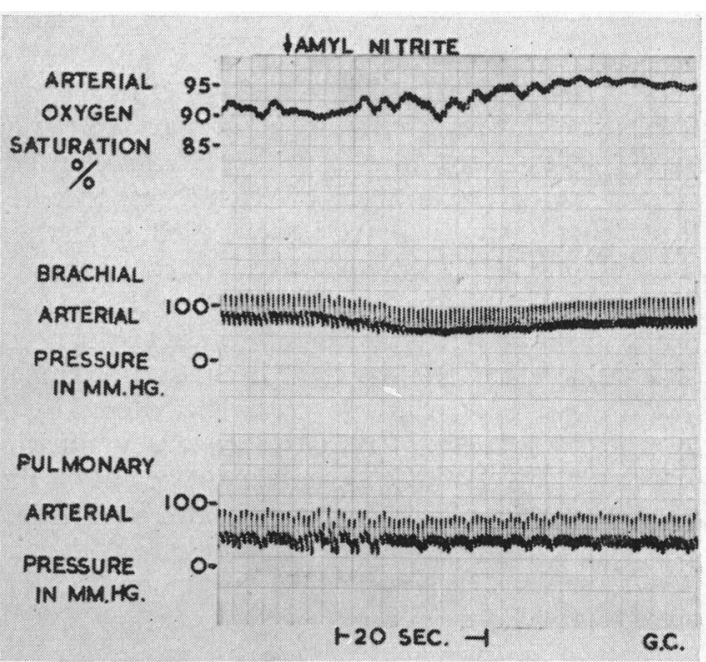

Fig. 20.-Fall in brachial arterial pressure, with no fall in arterial oxygen saturation or pulmonary arterial pressure, after amyl nitrite inhalation in a patient with atrial septal defect and pulmonary hypertension.

\section{Exercise}

The arterial oxygen saturation fell on exercise in all patients with a right-to-left shunt at rest. The extent of the fall was of little help in diagnosis in cyanosed patients. Exercise can, however, be of help in distinguishing primary pulmonary hypertension from pulmonary hypertension associated with a septal defect. The resting saturation was often about 85 per cent in primary pulmonary hypertension and did not fall with exercise unless there was associated lung disease. In patients with pulmonary hypertension and a shunt, the saturation almost always fell on exercise. 


\section{Squatting and Standing}

The effect of squatting and standing on the arterial saturation after exercise in cyanosed patients varied considerably. A fall in saturation on standing was strongly suggestive of Fallot's tetralogy but was seen also in some patients with Eisenmenger's complex. No benefit from squatting was found in patients with pulmonary atresia or pulmonary stenosis with reversed interatrial shunt. In some patients the effect of squatting was paradoxical, the saturation rising when the patient stood up and falling on squatting. This response is shown in Fig. 21 in a patient with pulmonary stenosis and reversed interatrial shunt. Similar results were seen in patients with transposition.

The reasons for the beneficial effect of squatting on the arterial oxygen saturation are not fully understood. Changes in both the systemic and venous sides of the peripheral circulation probably play a part. In the squatting position the intra-thoracic pressure tends to rise and the lung volume decreases. The femoral veins are thought to become kinked, so that the venous return to the right heart is reduced (Brotmacher, 1957). This tends to diminish any right-to-left shunt and should benefit all patients with a shunt and Fallot's tetralogy in particular, because the arterial saturation is very dependent on the amount of venous blood returning to the right heart. The effect of squatting on the arterial side is to raise the systemic pressure (SharpeyShafer, 1956). This might be due to kinking of the femoral or iliac vessels, which could reduce the size of the arterial bed. Such a rise might not be completely correctable by the compensatory action of the baroreceptor reflexes and might persist. An increase in systemic arterial pressure would be of particular benefit to patients with Fallot's tetralogy, because it would raise the right ventricular pressure and increase the pulmonary blood flow. The paradoxical effect in patients with transposition of the great vessels is more difficult to explain, but if there was a large pulmonary blood flow, the principal shunt would be from the pulmonary circulation to the systemic. If the arterial pressure was raised by squatting, this could reduce the shunt and produce a fall in saturation on squatting. Further work on the effects of squatting is clearly needed before the phenomena can be adequately explained.

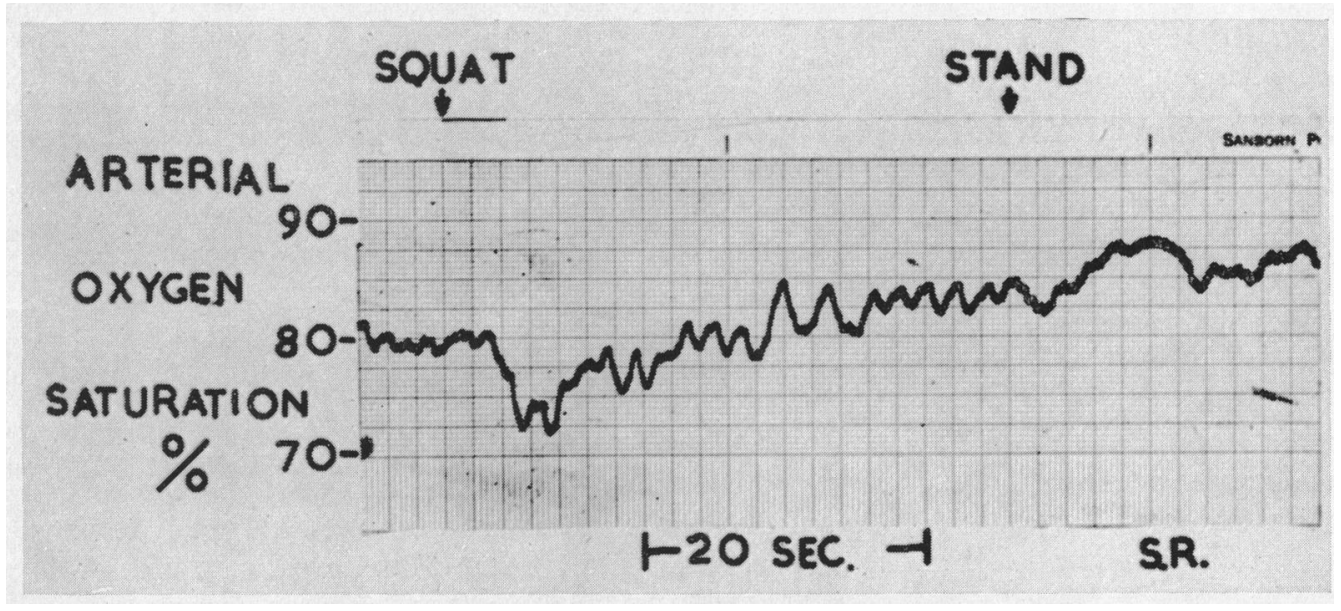

FIG. 21.-Fall in arterial oxygen saturation on squatting and rise in saturation on standing up, in a patient with pulmonary stenosis and reversed interatrial shunt.

\section{RESULTS In DifFerent Conditions}

The results in 32 patients with pulmonary hypertension and an intracardiac shunt are shown in Table III grouped on the basis of the site of shunt. A number of these patients were not clinically cyanosed at rest but for convenience all are included here.

Reversed Shunt at Aorto-Pulmonary Level. Six patients were studied in whom there was evidence of a reversed shunt at aorto-pulmonary level. In four the catheter was passed through a patent ductus into the descending aorta. In three there was a difference in the saturation measured in the right and left ears at rest. All had Type B response when studied sitting in a chair. In one a different response was obtained at cardiac catheterization with the patient lying flat and under these conditions the response was Type A. This was thought to indicate an associated ventricular 
septal defect; the right heart samples showed a left-to-right shunt at ventricular level and there was no pulmonary regugitation. The patient is still alive, so that the diagnosis has not been confirmed. Somewhat similar results were obtained in another patient in whom there was a difference in the arterial saturation measured in the two ears with the patient sitting, but this difference was abolished when he lay flat or exercised. It was thought that this finding could be due either to an associated ventricular defect, or to a peculiar lie of the patent ductus directing the flow of shunted blood upwards when the patient lay flat or increased the cardiac output on exercise. This patient is still alive and the diagnosis has not been confirmed; right heart samples showed a shunt at aortopulmonary level.

TABLE III

Results in 32 Patients with Pulmonary Hypertension and a Shunt

\begin{tabular}{|c|c|c|c|c|c|}
\hline \multirow[t]{2}{*}{ Level of shunt } & \multirow{2}{*}{$\begin{array}{l}\text { Number } \\
\text { of cases }\end{array}$} & \multirow{2}{*}{$\begin{array}{l}\text { Number with } \\
\text { equal pressures } \\
\text { in pulmonary } \\
\text { and systemic } \\
\text { circulations }\end{array}$} & \multirow{2}{*}{$\begin{array}{lc}\text { Valsalva response } \\
\text { Type A } & \text { Type B }\end{array}$} & \multicolumn{2}{|c|}{ Average arterial $\mathrm{O}_{2}$ saturation } \\
\hline & & & & Rest & Exercise \\
\hline $\begin{array}{l}\begin{array}{l}\text { Aorto-pulmonary } \\
\text { VSD+PDA }\end{array} \\
\text { VSD } \\
\text { Endocardial cushion } \\
\text { ASD ... }\end{array}$ & $\begin{array}{c}4 \\
2 \\
8 \\
7 \\
11^{*}\end{array}$ & $\begin{array}{l}4 \\
2 \\
7 \\
7 \\
2\end{array}$ & $\begin{array}{l}4 \\
2 \\
3 \\
5 \\
6\end{array}$ & $\begin{array}{c}93-89 \dagger \\
78 \\
90 \\
88 \\
91\end{array}$ & $\begin{array}{c}83-81 \dagger \\
76 \\
77 \\
76 \\
83\end{array}$ \\
\hline
\end{tabular}

* Two patients with ASD and pulmonary hypertension showed no shunt reversal after Valsalva's manœuvre.

$\dagger$ Arterial oxygen saturation in left ear.

Ventricular Septal Defect. In eight patients the shunt was thought to be at ventricular level only. These patients should strictly come into the category of cyanosis on effort for their resting saturations ranged from 92-87 per cent. Obvious cyanosis occurred on exercise; the type of response was variable and the arterial saturation fell with amyl nitrite in every patient in whom the drug was given. The effect of squatting was not tried in many but the results were variable. It was difficult to distinguish these patients from the seven in whom it was thought that there was either an endocardial cushion defect or both atrial and ventricular defects. The results of oximetric studies were intermediate between those in patients with ventricular defects and atrial defects, some showing Type A and others Type B responses.

Atrial Septal Defect. In 11 patients the shunt was thought to be solely at atrial level. Most of these became cyanosed only on effort and in two, no fall in saturation or shunt reversal could be demonstrated even after exercise. About two-thirds of this group showed a Type B response and amyl nitrite produced no fall in the arterial saturation. Most of these patients with ASD were thought to have developed pulmonary hypertension in adolescence or after pregnancy. In such cases there was often a difference between the pulmonary and systemic arterial pressures.

The result in 19 patients with different varieties of cyanotic congenital heart disease are shown in Table IV.

Fallot's Tetralogy. The results in patients with mild "acyanotic" Fallot's tetralogy have already been described. Five other cases with saturations ranging from 82 to 65 per cent are shown in Table IV. All had a type A response except one. In this patient amyl nitrite failed to influence the arterial saturation and squatting produced no benefit. A ventricular septal defect was proved at catheterization and the patient had had a Blalock operation. It is possible that most of the pulmonary blood flow was coming through the anastomosis and the patient should really be considered as a case of pulmonary atresia.

Pulmonary Atresia. Four patients with pulmonary atresia were studied. In three the diagnosis was confirmed at operation. All had a Type B response and no benefit from squatting was observed in the two in whom the effect of posture was studied. 
TABLE IV

Results in 19 Patients with Cyanosis at Rest

\begin{tabular}{|c|c|c|c|c|c|c|c|c|c|c|}
\hline $\begin{array}{l}\text { メ } \\
\text { L }\end{array}$ & 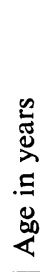 & 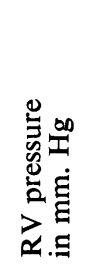 & 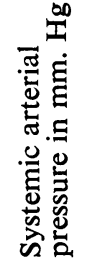 & 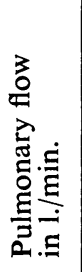 & 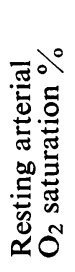 & 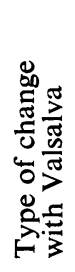 & 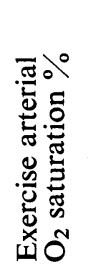 & 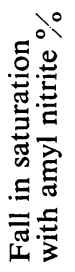 & 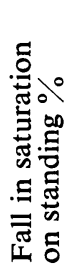 & Diagnosis and remarks \\
\hline M & 4 & & & & 82 & A & 75 & & & Fallot's tetralogy: angio. \\
\hline M & 9 & $85 / 10$ & $85 / 55$ & $1 \cdot 8$ & 80 & A & 70 & 4 & & Fallot's tetralogy: autopsy \\
\hline $\mathbf{M}$ & 10 & $100 / 0$ & $105 / 75$ & $1 \cdot 4$ & 70 & A & & & & Fallot's tetralogy \\
\hline $\mathbf{F}$ & 25 & $120 / 0$ & $135 / 80$ & $2 \cdot 0$ & 65 & B & & 0 & 0 & Fallot's tetralogy: autopsy \\
\hline $\mathbf{M}$ & 26 & & & & 78 & $\bar{A}$ & 58 & & 7 & Fallot's tetralogy \\
\hline $\mathbf{M}$ & 12 & $90 / 2$ & $82 / 58$ & $1 \cdot 6$ & 75 & B & & 0 & 0 & Pulmonary atresia \\
\hline $\mathbf{F}$ & 20 & $125 / 0$ & $127 / 70$ & $4 \cdot 0$ & $\begin{array}{l}80 \\
88\end{array}$ & $\mathbf{B}$ & 60 & & 0 & Pulmonary atresia \\
\hline $\mathbf{F}$ & 24 & & & & 88 & B & 65 & & & Pulmonary atresia \\
\hline $\mathbf{M}$ & 40 & $105 / 3$ & $105 / 50$ & $4 \cdot 5$ & 70 & B & & & & Pulmonary atresia: operation \\
\hline $\mathbf{F}$ & 9 & $100 / 5$ & & $2 \cdot 0$ & 83 & & & 0 & 5 & Pulmonary stenosis rev. I-A shunt \\
\hline $\mathbf{F}$ & 13 & $150 / 0$ & & 1.0 & 70 & B & & 0 & 0 & Pulmonary stenosis: autopsy \\
\hline $\mathbf{M}$ & 17 & & $105 / 90$ & $1 \cdot 7 \dagger$ & 60 & B & & & 8 & Tricuspid atresia \\
\hline $\mathbf{F}$ & 8 & $24 / 0$ & $100 / 70$ & 1.8 & 86 & A & 75 & & 5 & Reversed interatrial shunt \\
\hline $\mathbf{F}$ & 14 & $8 *$ & & & 83 & B & 65 & & 0 & Reversed interatrial shunt \\
\hline M & 32 & $8 / 0$ & $95 / 60$ & 3.4 & 74 & B & & & & Reversed interatrial shunt \\
\hline $\mathrm{F}$ & 13 & $90 / 0$ & $85 / 0 \ddagger$ & $1 \cdot 8$ & 82 & B & 65 & & & Transposition + PS + ASD \\
\hline $\mathbf{F}$ & 20 & & & & 78 & B & 60 & & 9 & Transposition+PS: angio. \\
\hline $\mathrm{F}$ & 7 & $95 / 0$ & & $10 \cdot 0$ & 82 & $\mathbf{A}$ & 65 & & 10 & $\begin{array}{l}\text { Transposition +mild PS +ASD+ } \\
\text { VSD }\end{array}$ \\
\hline $\mathrm{F}$ & 17 & $75 / 5$ & $95 / 55$ & $10 \cdot 0$ & 85 & B & 72 & & 0 & Transposition: dextrocardia ASD \\
\hline
\end{tabular}

Pulmonary Stenosis With Reversed Interatrial Shunt. Two patients with resting saturations of 83 and 70 per cent were studied; both showed a Type B response and derived no benefit from squatting. Amyl nitrite had no effect on the arterial oxygen saturation. In one, amyl nitrite was given at catheterization and resulted in a rise in right ventricular pressure. This finding was also observed in two other patients with pulmonary stenosis and an intact ventricular septum.

Tricuspid Atresia. Only one patient was studied. The arterial response to Valsalva's manœuvre was square wave in this patient, so that the change in saturation was of Type B. This patient derived benefit from squatting.

Reversed Interatrial Shunt. These three patients had arterial saturations of 83, 86, and 74 per cent at rest. No adequate cause for the shunt from right to left was found. One had evidence of left ventricular hypertrophy and may have had a functional equivalent of tricuspid atresia. The change in saturation with Valsalva's manœuvre varied but in two there was a fall in saturation on standing and a rise on squatting.

Transposition. The four patients with this diagnosis had complicated lesions and the complete diagnosis was uncertain. In two the pulmonary blood flow was increased and in one of these the paradoxical effect of squatting and standing was well marked.

\section{SUMMARY}

The measurement of the effect of various simple manœuvres on the arterial oxygen saturation has been described. An ear oximeter was used to record the change in arterial saturation with Valsalva's manœuvre, amyl nitrite inhalation, exercise, oxygen breathing, and changes in posture.

Useful information about the presence and size of atrial defects can be obtained. In patients with uncomplicated atrial septal defect, shunt reversal after Valsalva's manœuvre at rest indicates 
that the defect is small. If shunt reversal only occurs after Valsalva's manœuvre after exercise, the defect is moderate in size; and, if the defect is large, no shunt reversal occurs because the arterial pressure response to Valsalva's manœuvre is square wave in type. Observation of the effect of Valsalva's manœuvre on the arterial oxygen saturation is a simple means of checking whether an atrial defect has been completely closed at operation.

The distinction between mild Fallot's tetralogy and pulmonary stenosis with normal aortic root can be made by measuring the effect of exercise, amyl nitrite inhalation, and squatting on the arterial oxygen saturation.

In patients with Fallot's tetralogy, the arterial oxygen saturation falls precipitously on exercise: it falls about 5 per cent after amyl nitrite inhalation, and about 10 per cent on standing up from the squatting position after exercise. None of these changes occur in patients with pulmonary stenosis with normal aortic root.

In cyanotic patients the difference between cyanosis due to lung disease and cyanosis due to a right-to-left shunt can be determined by measuring the effect of oxygen breathing on the arterial saturation. In patients with lung disease the arterial oxygen saturation rises rapidly and in an exponential manner to normal, while in patients with a shunt it rises slowly and in a linear manner to a level about 8 per cent above its initial value.

In patients with a right-to-left shunt, a rough estimate of the systemic and pulmonary flows can be obtained.

In patients with pulmonary hypertension and an intracardiac shunt, the level of the shunt can often be determined by oximetry, and in other cyanotic lesions information can be obtained that is sometimes helpful in arriving at a diagnosis.

My thanks are due to the physicians of the National Heart Hospital for allowing me to study their patients and to Dr. Paul Wood in particular for helpful criticism.

\section{REFERENCES}

Bolt, W., Michel, D., Schulte, W., Valentin, H., and Venrath, H. (1956). Ztschr. Kreislaufforsch., 45, 402.

Brabrook-Norman, J. C. (1954). J. Soc. cardiol. Tech., 2, 111.

Brotmacher, L. (1957). Brit. Heart J., 19, 567.

Comroe, J. H., and Dripps, R. D. (1950). The Physiological Basis for Oxygen Therapy. C. C. Thomas, Springfield, Illinois.

Hamilton, W. F., Woodbury, R. A., and Harper, H. T. (1944). Amer. J. Physiol., 141, 42.

Lee, G. de J., and Gimlette, T. M. D. (1957). Brit. med. J., 1, 1278.

, (1958). Personal communication.

McIlroy, M. B. (1958). Brit. Heart J., 20, 287.

Sharpey-Shafer, E. P. (1955). Brit. med. J., 1, 693.

, (1956). Brit. med. J., 1, 1072.

Stott, F. D. (1953). J. sci. Instrum., 30, 120. 